\title{
A STUDY OF THE RETENTION OF METASTABLE PHASES IN QUENCHED URANIUM-NIOBIUM-ZIRCONIUM TERNARY ALLOYS
}

\author{
R. H. Cooper, Jr
}

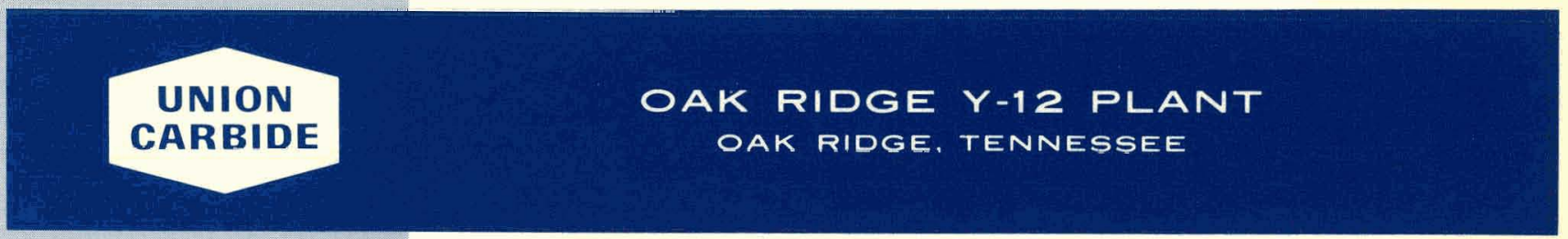

prepared for the U.S. ENERGY RESEARCH AND DEVELOPMENT ADMINISTRATION under U.S. GOVERNMENT Contract W-7405 eng 26

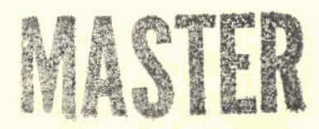




\section{DISCLAIMER}

This report was prepared as an account of work sponsored by an agency of the United States Government. Neither the United States Government nor any agency Thereof, nor any of their employees, makes any warranty, express or implied, or assumes any legal liability or responsibility for the accuracy, completeness, or usefulness of any information, apparatus, product, or process disclosed, or represents that its use would not infringe privately owned rights. Reference herein to any specific commercial product, process, or service by trade name, trademark, manufacturer, or otherwise does not necessarily constitute or imply its endorsement, recommendation, or favoring by the United States Government or any agency thereof. The views and opinions of authors expressed herein do not necessarily state or reflect those of the United States Government or any agency thereof. 


\section{DISCLAIMER}

Portions of this document may be illegible in electronic image products. Images are produced from the best available original document. 
Printed in the United States of America. Available from National Technical Information Service

U.S. Department of Commerce

5285 Port Ruyal Road, Springfield, Virginia 22161

Price: Printed Copy \$4.00; Microfiche $\$ 2.25$

This report was prepared as an account of work sponsored by the United States Government. Neither the United States nor the Energy Research and Development Administration, nor any of their employees, nor any of their contractors, subcontractors, or their employees, makes any warranty, express or implied, or assumes any legal liability or responsibility for the accuracy, completeness or usefulness of any information, apparatus, product or process disclosed, or represents that its use would not infringe privately owned rights. 


\title{
A STUDY OF THE RETENTION OF METASTABLE PHASES IN QUENCHED URANIUM-NIOBIUM-ZIRCONIUM TERNARY ALLOYS
}

\author{
R. H. Cooper, Jr \\ Quality Evaluation Department \\ Y.12 Assembly Division
}

\begin{abstract}
Adapted from a thesis that was submitted to The University of Tennessee in partial fulfillment of the requirements for the degree Master of Science
\end{abstract}

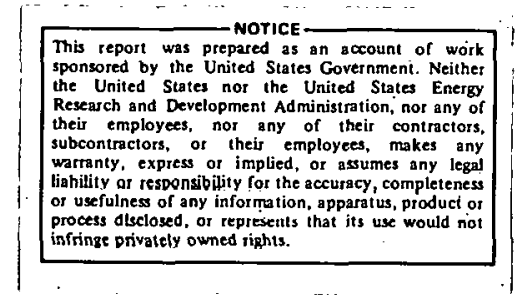

Oak Ridge $Y$-12 Plant

P. O. Box Y, Oak Ridge, Tennessee 37830

Prepared for the US Energy Research and Dovelopment Administration

Under US Government Contract W-7405-eng-26 


\begin{abstract}
A metastable or transitional phase diagram for the uranium-rich section of the uranium-niobium-zirconium ternary system was proposed for alloys quenched from $850^{\circ} \mathrm{C}$. A review of those alloys having a $B C C$ and a displaced $B C C$ structure revealed a linear relation between the BCC lạttice parameters and alloy content, which ajpruximately obèys Vegard's Law over the range of compositions investigated. The monoclinic angle, $\hat{\gamma}$, was found to be linearly related to the niobium and zirconium contents. Metallographic examination of the samples having a monoclinic structure indicated that these samples had a Widmanstatten structure. The DPH hardness of all alloys regardless of crystal structure was found to bc related to lie nioblum and zirconium contents by the following equation: $\mathrm{DPH}=44.9+0.45 \mathrm{Nb}^{2}+8.8 \mathrm{Zr}$.
\end{abstract}




\section{CONTENTS}

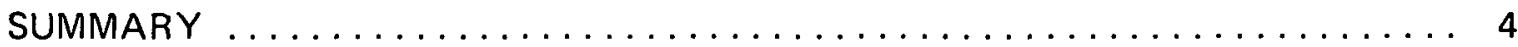

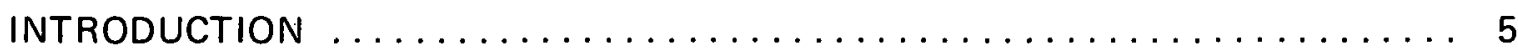

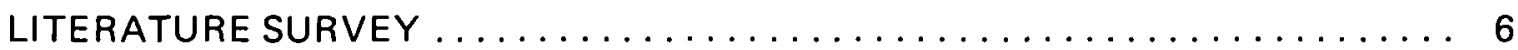

Uranium-Niobium Binary System $\ldots \ldots \ldots \ldots \ldots \ldots \ldots \ldots \ldots \ldots \ldots \ldots \ldots \ldots \ldots$

Uranium-Zirconium Binary System $\ldots \ldots \ldots \ldots \ldots \ldots \ldots \ldots \ldots \ldots \ldots \ldots \ldots \ldots \ldots$

Uranium-Niobium-Zirconium Ternary System $\ldots \ldots \ldots \ldots \ldots \ldots \ldots \ldots \ldots \ldots, 12$

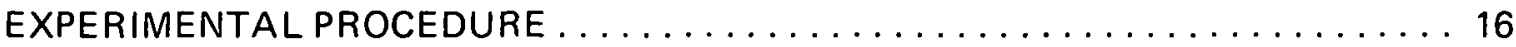

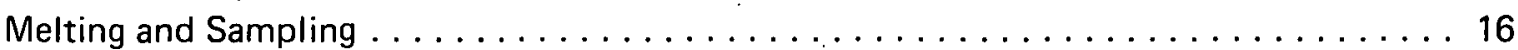

Homogenization and Forging ........................... 16

Metallographic Preparation and X-Ray Diffraction Technique ............. 17

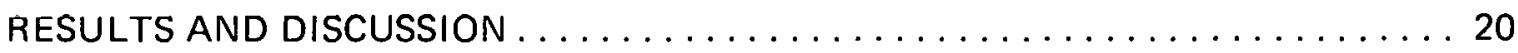

General Ingot Characterization ............................. 20

Recrystallization .................................... 20

Characterization of Cubic Lattice Parameters . . . . . . . . . . . . . . . . 21

Gamma-s and Gamma-o Structures . . . . . . . . . . . . . . . . . . . . . . . . . 25

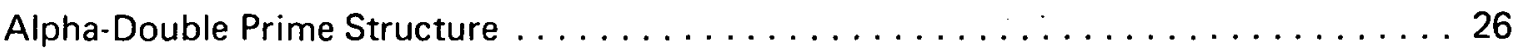

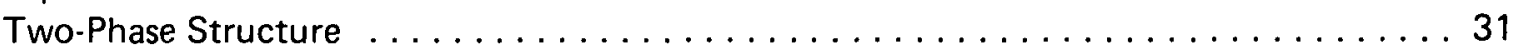

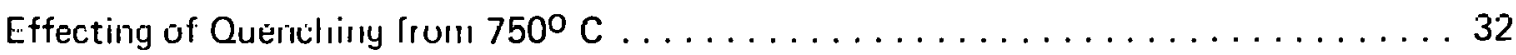

Relationship between Alloy Content and Microhardness $\ldots \ldots \ldots \ldots \ldots \ldots \ldots . \ldots 33$

Transitional Phase Diagram .............................. 34

CONCLUSIONS AND RECOMMENDATIONS $\ldots \ldots \ldots \ldots \ldots \ldots \ldots \ldots \ldots \ldots$

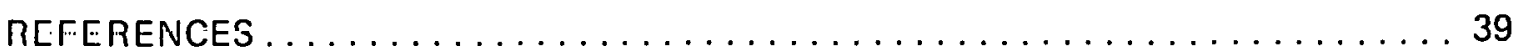

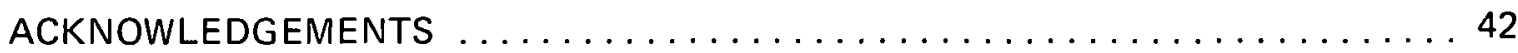




\section{SUMMARY}

A metastable or transitional phase diagram for the uranium-rich section of the uranium-niobium-zirconium ternary system was proposed for alloys quenched from $850^{\circ} \mathrm{C}$. This transitional phase diagram was determined primarily from the results of $X$-ray diffraction and has important differences from the one suggested by Dwight and Mueller. The boundary for gamma-phase retention is proposed to be a straight line connecting the 23.8 and 24 atom percent alloys in the uranium-niobium and uranium-zirconium binary systems, respectively. An area of gamma-o stability was observed, but was found to be compressed significantly from that proposed by Dwight and Mueller. Furthermore, the $\alpha^{\prime} / \alpha^{\prime \prime}$ boundary in this diagram was found to be displaced from the Dwight and Mueller boundary in the direction of lower alloy content by 2 to 3 atom percent.

A review of those alloys having a $B C C$ and a displaced $B C C$ structure revealed a linear relation between the $B C C$ lattice parameters and alloy content, which approximately obeys Vegard's Law over the range of compositions investigated. The monoclinic angle, $\hat{\gamma}$, was found to be linearly related to the niobium and zirconium contents. Metallographic examination of the samples having a monoclinic structure indicated that these samples had a Widmanstatten structure. The DPH hardness of all alloys regardless of crystal structure was found to be related to the niobium and zirconium contents by the following equation: $\mathrm{DPH}=44.9+0.45 \mathrm{Nb}^{2}+8.8 \mathrm{Zr}$. 


\section{INTRODUCTION}

As a result of the present energy crisis, commitments to accelerate the fabrication and development of various nuclear reactor designs have been initiated. This anticipated progress in reactor design will stimulate the need for high-density shielding materials and reactor fuels which can be fabricated easily, heat treated to a wide range of mechanical properties, and maintained chemically inert in nominally atmospheric conditions. Use of unalloyed uranium in these applications has been found to be impractical. The primary factor that curtails the use of unalloyed uranium is that at low temperatures uranium atoms are arranged in a complex orthorhombic crystal lattice. This phase of uranium is highly susceptible to corrosion and has anisotropic properties which result in texturing during fabrication, and other undesirable directional properties. Fabricated parts having this textured structure are dimensionally unstable during thermal cycling and radiation exposure.

However, from $760^{\circ} \mathrm{C}$ to the melting point, the BCC gamma phase of uranium is stable. In the gamma structure, uranium has been observed to have extended solubility for molybdenum, niobium, zirconium, and titanium. Rapid quenching of some of these alloys from this region will result in the retention of gamma at room temperature. Evaluation of this metastable gamma phase has revealed that such materials may have improved corrosion resistance and possess more nearly isotropic properties, thus improving dimensional stability after radiation exposure and thermal cycling. In addition, low-temperature aging of this metastable phase can produce a wide range of yield strengths and elongations. These favorable characteristics make the gamma-stabilized uranium alloys attractive from a technological viewpoint.

These factors have prompted considerable effort in the development and evaluation of dilute binary and ternary uranium alloys with molybdenum, niobium, and zirconium. At present, these studies suggest that an optimum combination of strength and corrosion resistance can be realized with alloys in the uranium-niobium-zirconium system and, in particular, with a uranium-16.6 atom percent niobium-5.6 atom percent zirconium (U-16.6 $\mathrm{Nb}-5.6 \mathrm{Zr}$ ) alloy.

Previous studies of both uranium-niobium and uranium-zirconium alloys have shown that numerous transitional (or metastable) phases of varying crystal structures are produced on quenching. Efforts to control the mechanical properties and to maintain dimensional stability in the ternary uranium alloys will require the identification and characterization of these metastable phases as well as a knowledge of their low-temperature phase transformation kinetics. Determination of the relationship between alloy content and the crystal structures produced on quenching is an important and presently inadequately answered question in ternary uranium-niobium-zirconium alloys. Therefore, the object of this study was to identify and characterize the transitional structures resulting from quenching various uranium-niobium-zirconium alloys taken from the uranium-rich corner of the ternary system. This study was carried out at the Oak Ridge Y-12 Plant. (a)

(a) Operated by the Union Carbide Corporation's Nuclear Division for the US Energy Research and Development Administration. 


\section{LITERATURE SURVEY}

In the solid state, unalloyed uranium has been found to be an allotropic material having a room-temperature alpha phase, an intermediate beta phase, and a high-temperature gamma phase. Both the alpha and beta phases have complex crystal structures which have required extensive evaluation to characterize. The alpha phase is stable to $667^{\circ} \mathrm{C}$; and, initially, was thought to be cubic with $a=3.430 \AA$.(1) Subsequent evaluation suggested that this low-temperature phase may have been monoclinic; (2) however, later work has confirmed this allotrope to be a complex orthorhombic structure having lattice parameters of $a=2.854 \AA, b=5.869 \AA$, and $c=4.955 \AA$. (3) This stucture has been described as resembling a hexagonal arrangement in which successive basal planes have been shifted out of line by approximately 0.10 angstrom, giving the structure the appearance of having a series of corrugations. ${ }^{(4)}$ I his structure has similarities with the strongly covalent compound $\mathrm{PCl}_{5},(5)$ which is thought to account for the low solubility of alloying elements having a similar atomic radius. In addition, this structural arrangement tends to contract along the $b$ axis while the $a$ and $c$ axes expand with increasing temperature. Similar anisotropic trends are observed in both thermal and electrical conductivity properties. Compounding these anisotropic properties is the tendency for the alpha phase to develop a texture when rolled at temperatures ranging from 20 to $400^{\circ} \mathrm{C}$. This trend results in a material that is highly unsuitable for nuclear applications.

Much like the alpha phase, beta uranium also possesses a complex structure. Although this structure has not been resolved in detail, there is agreement that the structure is tetragonal, having lattice parameters of $a=b=10.754 \AA$ and $c=5.623 \AA$ at $700^{\circ} \mathrm{C}$. Although the beta structure is ductile, the transformation of beta to alpha produces cracks and reduces the possibility of fabricating the material in this temperature range.

The gamma phase of uranium is stable from $771^{\circ} \mathrm{C}$ to the melting point. This phase is BCC, having a lattice parameter of $3.53 \AA$. In view of the more nearly isotropic properties, ease of fabrication, and sluggishness of decomposition with alloy additions, the gamma phase has received increasing engineering interest.

Although unalloyed uranium has several metallurgical drawbacks that limit the engineering usage of the material, dilute alloys that result in the retention of gamma at room temperature have been found to resolve some of these problems. ${ }^{(6)}$ In turn, these observations have prompted the extensive evaluation of uranium alloys of niobium, zirconium, and molybdenum. One product of this extensive evaluation has been the increased engineering utilization of alloys from the uranium-rich corner of the uranium-niobium-zirconium ternary system. Before discussing this ternary system in particular, a review of the properties of the uranium-niobium and uranium-zirconium binary systems is appropriate.

\section{URANIUM-NIOBIUM BINARY SYSTEM}

Initial efforts to determine the uranium-niobium binary phase diagram were carried out by Sawyer. (7) Later, using improved experimental techniques and higher-purity materials, revisions to Sawyer's phase relations were made by Pfeil $(8)$ and Rogers. ${ }^{(9)}$ A review of these efforts has led to much controversy over some aspects of the uranium-niobium phase 
diagram. However, the portion of the phase diagram indicated by dark lines in Figure 1 does not appear to be in question in the literature. A review of this diagram indicates the following: (1) there is a continuous series of solid solutions between the BCC gamma niobium phase and the BCC gamma uranium phase; (2) this gamma phase goes through a monoeutectoid reaction below $645^{\circ} \mathrm{C}$; (3) a miscibility gap is formed between gamma uranium and gamma niobium in the region between 10 to 72 atom percent niobium, with a maximum at $975^{\circ} \mathrm{C}$ and 52.3 atom percent niobium.

The principal discrepancies in the phase diagram are associated with the solubility of niobium in beta uranium and the location of the beta-to-alpha transformation temperature. Although these differences of opinion could be the result of investigative techniques, sluggishness of transformations in uranium-niobium alloys, or differences in the impurity levels, the resulting disagreement has significant impact on classifying the nature of the beta-to-alpha reaction. Pfeil, et al, (8) found the beta-to-alpha temperature to be $667^{\circ} \mathrm{C}$; however, Rogers, et al, $(9)$ located the transformation at $664^{\circ} \mathrm{C}$. Since the beta-to-alpha transformation in pure uranium occurs at approximately $667^{\circ} \mathrm{C}$, placement of the beta-to-alpha isotherm in the binary system above or below the pure metal transformation temperature indicates whether the beta-to-alpha reaction is peritectoid or eutectoid. The impact of this placement of the beta-to-alpha transformation temperature on the phase diagram is shown schematically in Figure 2.

Quenching of dilute uranium-niobium alloys from the single-phase gamma region has been shown to produce a variety of complex metastable phases. The resulting crystal structures of these transitional phases appears to be primarily a function of the niobium content; however, the quenching procedure has been found to have a secondary effect. These transitional structures can be classified in one of the following groups:

1. Alpha prime $\left\langle\alpha^{\prime}\right\rangle$ is an extension of the orthorhombic structure of pure uranium in the uranium-niobium system for alloys containing less than 10 atom percent niobium.

2. Alpha double prime $\left(\alpha^{\prime \prime}\right)$ is a monoclinic structure in which the cell dimensions are approximately the same as the orthogonal cell dimensions observed in the alpha prime material; however, the cell angle between the $a$ and $b$ axes is greater than 90 degrees. This crystal symmetry is seen in alloys containing 10 to 16 atom percent niobium.

3. Gamma-o $\left(\gamma^{0}\right)$ is a transitional phase having tetragonal symmetry and has been reported for alloys containing between 16 to 21 atom percent niobium.

The first two phases are thought to be formed martensitically by a shearing motion of one set of $\{112\}$ cubic phases in a $\langle 111\rangle$ cubic direction. $(10,11)$ The degree of departure of the $\alpha^{\prime}$ and $\alpha^{\prime \prime}$ structures from the alpha uranium orthorhombic structure has been proposed to be a function of the stiffness of the lattice against shear by alloying. $(12,13)$

Using both hot and cold-stage $X$-ray diffraction techniques, Jackson $(14)$ recently has studied the variations of the lattice parameters of the transitional phases of various alloys as a function of temperature. As a result of this investigation, continuous, athermal, and reversible transformations between the $\alpha^{\prime}, \alpha^{\prime \prime}$, and $\gamma^{\circ}$ transitional phases were observed on heating and cooling. Jackson has illustrated the results of this experiment in a "transition phase diagram" (Figure 3). 


\section{URANIUM-ZIRCONIUM BINARY SYSTEM}

The salient features of the uranium-zirconium binary system are: (1) a continuous series of solid solutions between gamma zirconium and gamma uranium; (2) a gamma miscibility gap existing between 14.5 and 57 atom percent zirconium, with a maximum of $740^{\circ} \mathrm{C}$ and 34

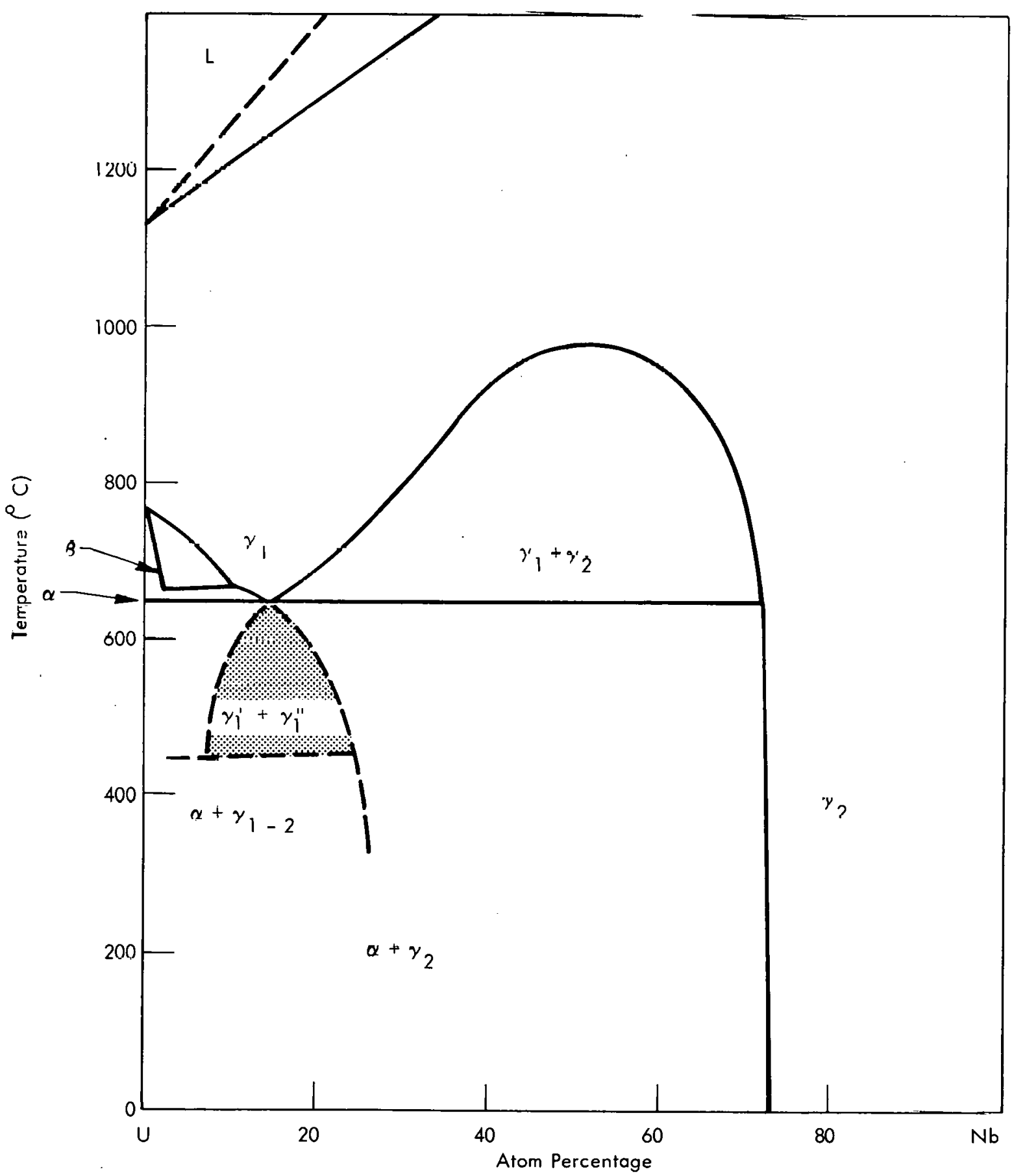

Figure 1. PHASE RELATIONSHIPS IN THE URANIUM-NIOBIUM SYSTEM. (The Solid Lines Represent Equilibrium Phase Relationships as Determined by Pfeil, et al $(8)$ and Rogers, et al. $(9)$ 


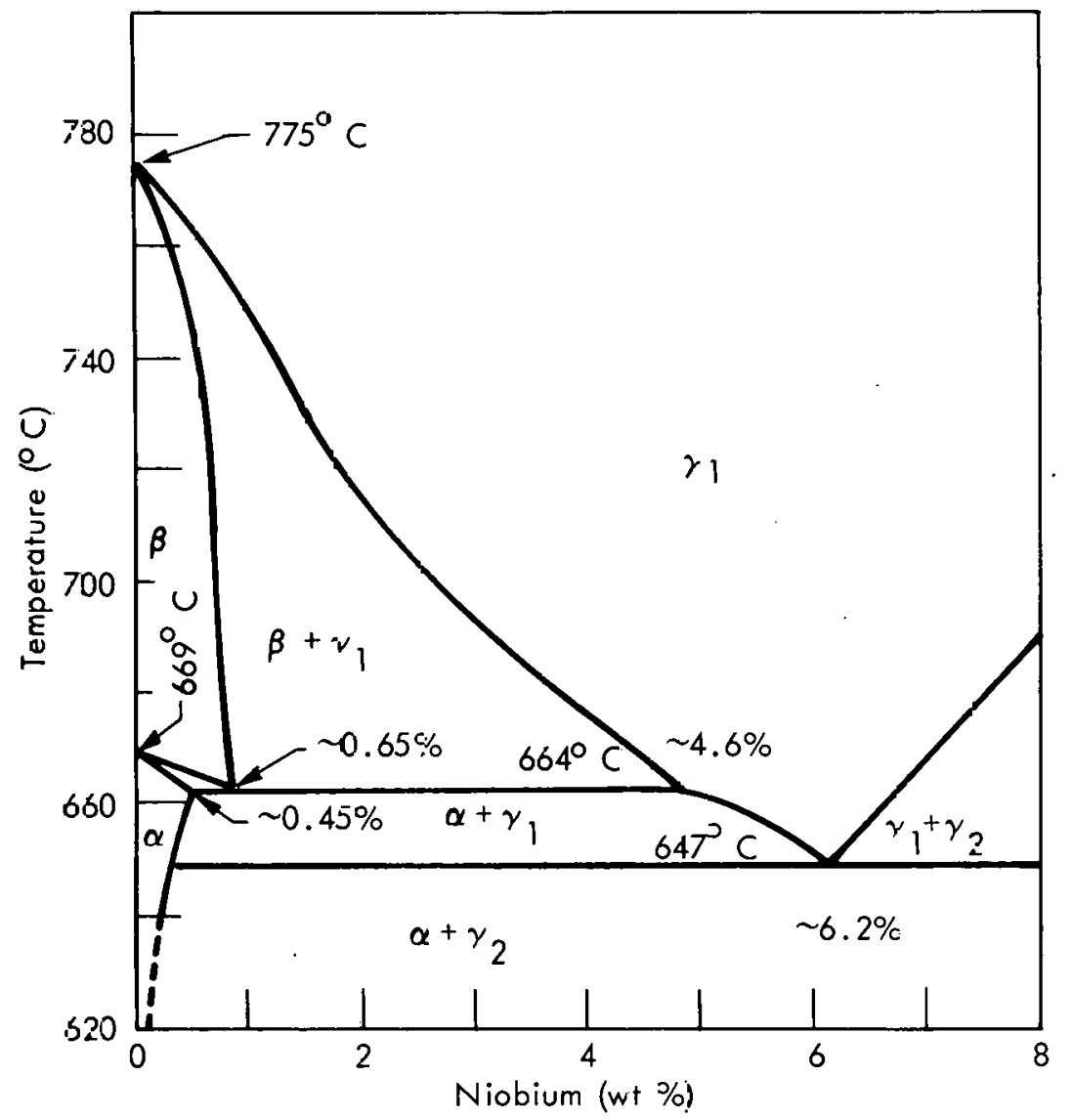

(a) According to Rogers et al. 9

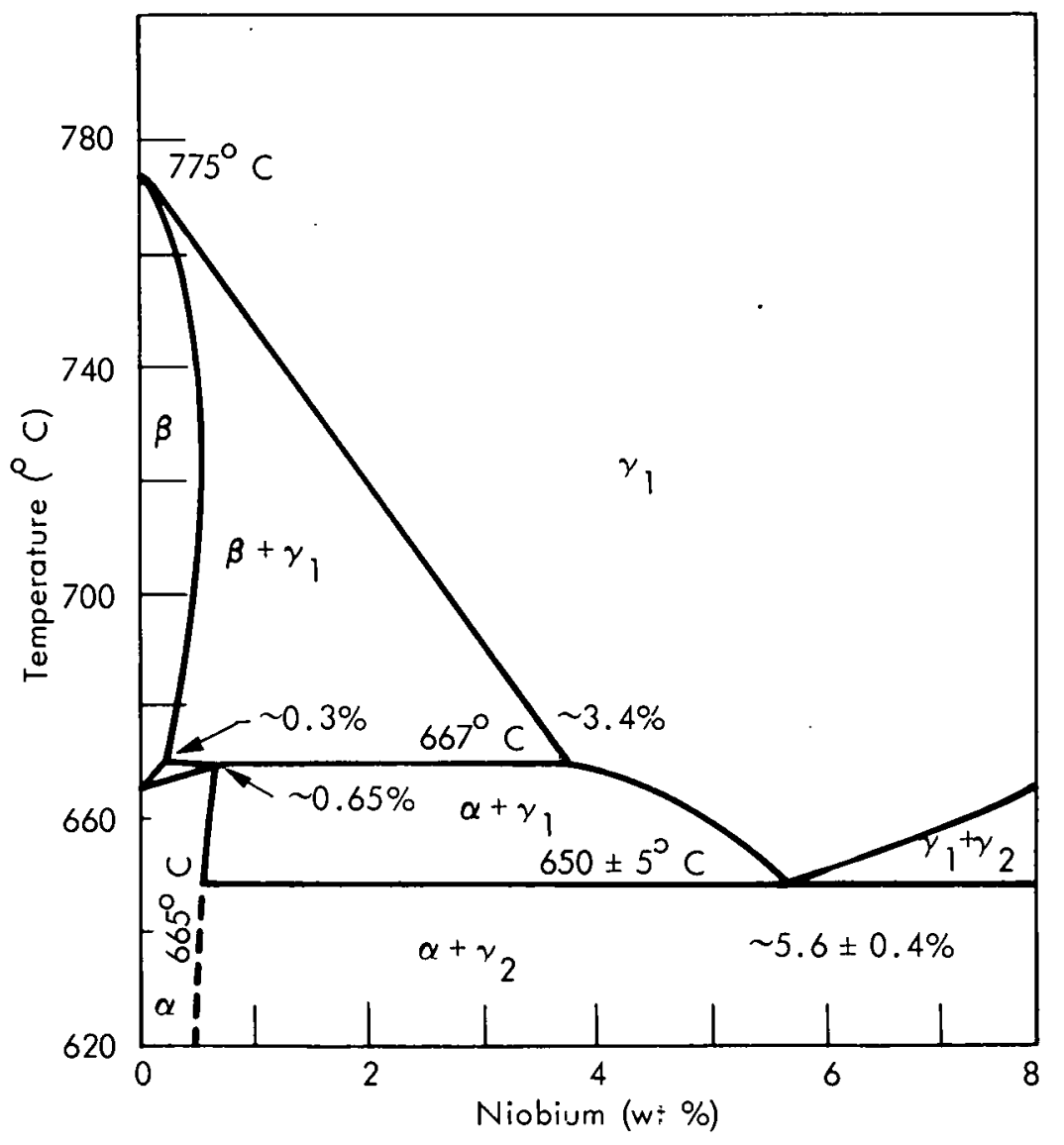

(b) According to Pfeil et al. 8

Figure 2. URANIUM-NIOBIUM EQUILIBRIUM DIAGRAMS. 
atom percent; (3) a gamma eutectoid reaction is present at 85.5 atom percent uranium at $693^{\circ} \mathrm{C} ;(4)$ an intermetallic compound, delta, was found to be stable below $600^{\circ} \mathrm{C}$ and has a BCT structure.

The initial uranium-zirconium phase diagram was proposed by Summer-Smith. (15) This work suggested the presence of a eutectoid reaction and the occurrence of the delta phase which was judged to be a metastable phase and was not added to this phase dlagram. Later, Duffey (16) confirmed that the delta was an equilibrium phase. Paralleling work in the uranium-niobium system, there currently is considerable controversy over classifying the beta-to-alpha reaction as eutectoid or peritectoid. At present, the eutectoid reaction appears to be the more favorable; therefore, the phase diagram shown in Figure 4 was drawn, assuming the eutectoid reaction. (17)

Investigations of the structure of various uranium-zirconium alloys quenched from the high-temperature gamma phase region have revealed the existence of the alpha prime

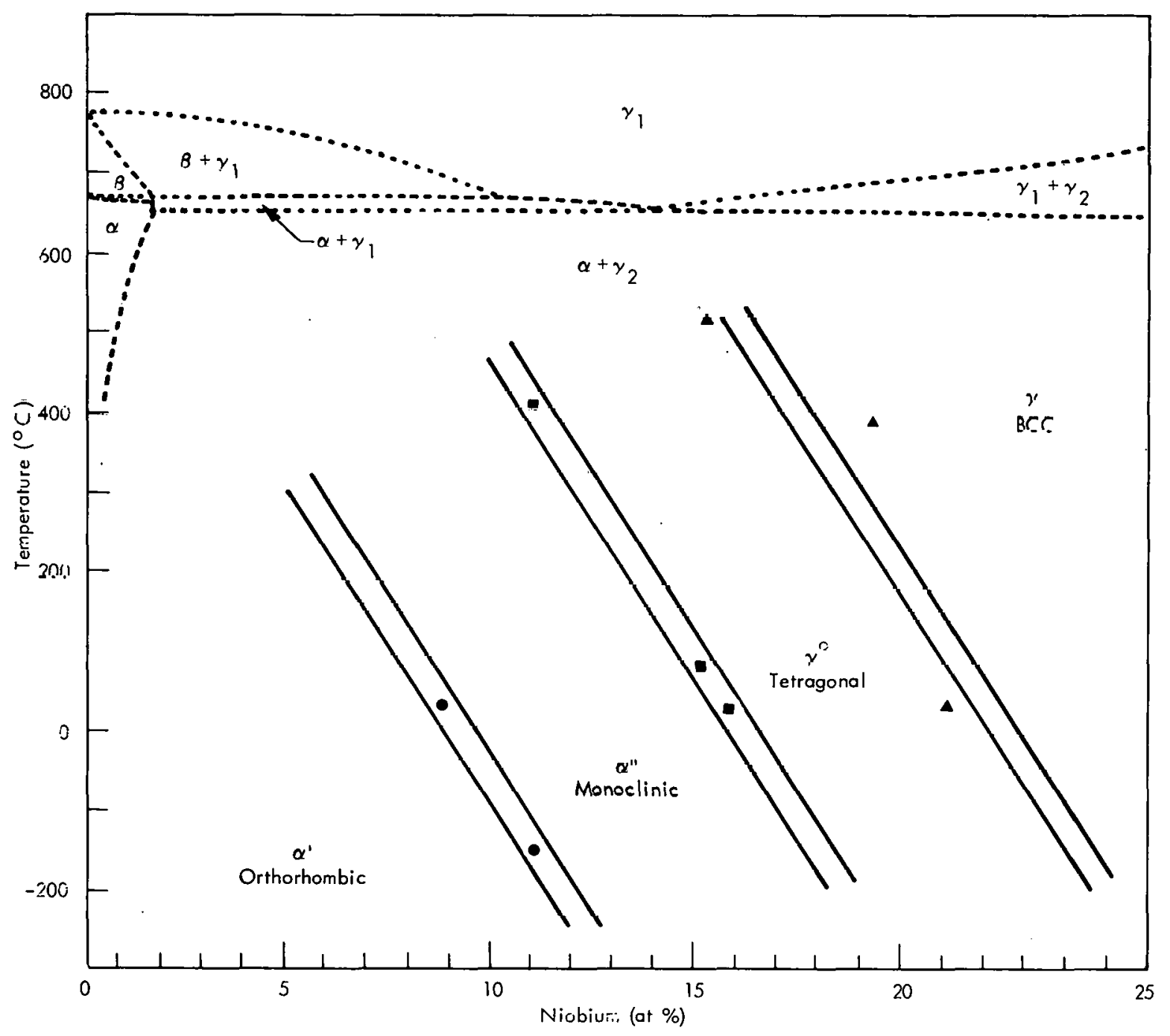

Figure 3. TRANSITION PHASE DIAGRAM FOR URANIUM-BASED NIOBIUM ALLOYS. (The Dotted Lines Represent Equilibrium Phase Boundaries; the Solid Lines Represent Nonequilibrium Phase Boundaries) 


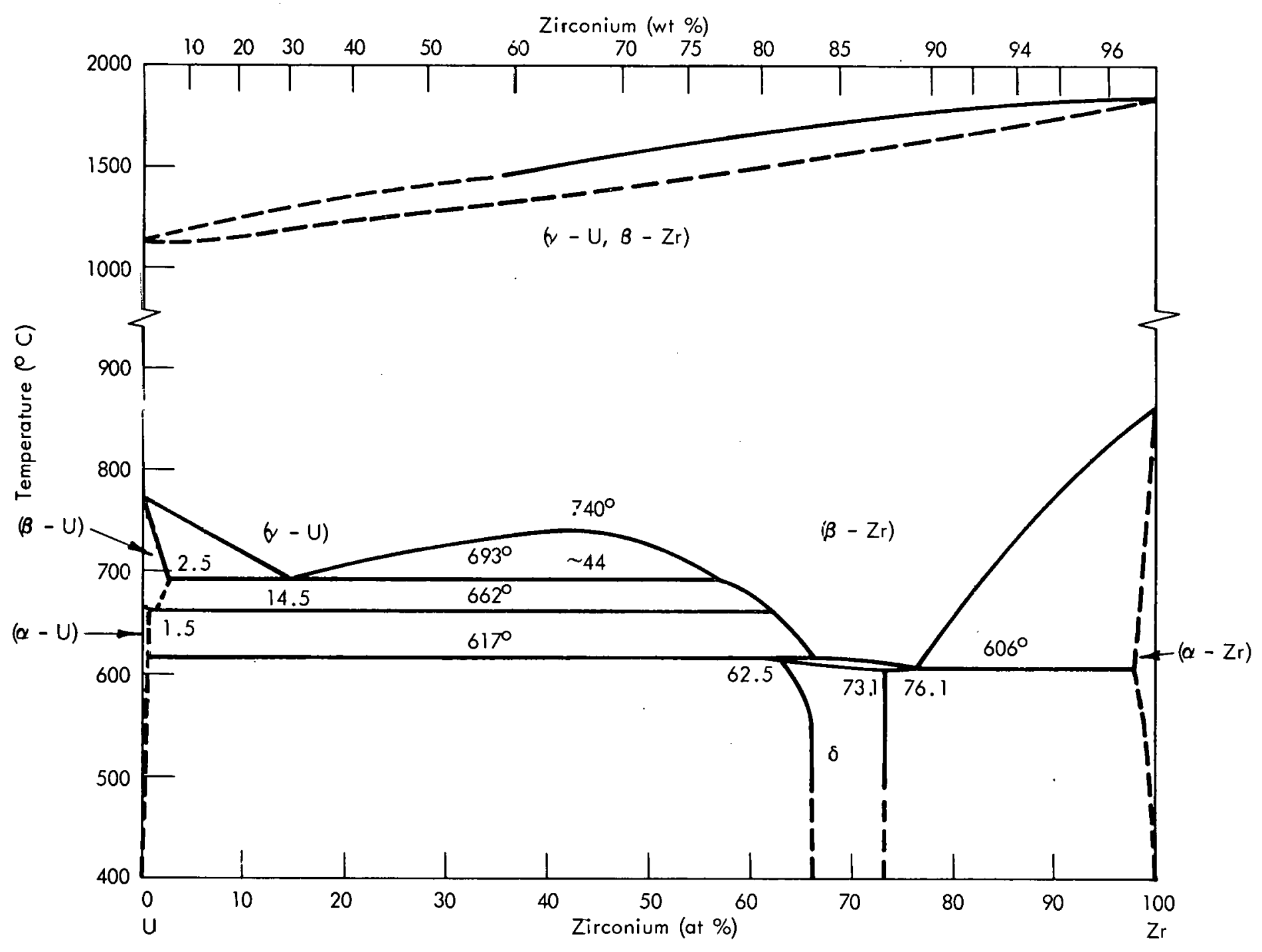

Figure 4. URANIUM-ZIRCONIUM EQUILIBRIUM DIAGRAM. 
transitional phase in alloys containing less than 24 atom percent zirconium, while uranium alloys containing more than 24 atom percent zirconium have the retained gamma structure at room temperature. $(18,19,20)$ Tangri $(12,13)$ suggested that the lack of the alpha double prime in the uranium-zirconium system could be predicted, based on the empirical observations of the $\alpha^{\prime}$-to- $\alpha^{\prime \prime}$ transformation in the uranium-niobium and uraniummolybdenum systems. From measurements of bond length in alpha-phase uranium, the shape and size of the uranium atom may be assumed to be an ellipsoid, with a major axis length of $3.39 \AA$ and parallel to $b$ and a minor axis length of $2.86 \AA$ and parallel to $a$. If the ellipsoid-shaped uranium atoms are replaced with molybdenum and niobium atoms, assumed to be hard spheres of diameter $2.724 \AA$ and $2.852 \AA$, respectively, a decrease in the b parameter with alloy content would be anticipated and has been observer experimentally. $(12,13)$ In addition, it has been noted that the $\alpha^{\prime}$-to- $\alpha^{\prime \prime}$ transition occurs when the b parameter der.reases to a value of $5.80 \AA$ in the nobsum and molybuterium systems. Since the approximate diameter of the zirconium atom is $3.12 \AA$, the barameter would be expected to increase from $5.869 \AA$ with the addition of zirconium. Therefore, if the alpha double prime phase exists when $b<5.80 \AA$, then it would not be expected to appear in the zirconium alloys.

\section{URANIUM-NIOBIUM-ZIRCONIUM TERNARY SYSTEM}

The initial effort to determine the uranium-niobium-zirconium ternary phase diagram was carried out by Dwight and Mueller, $(21)$ and the result is shown schematically in Figure 5 . As would be expected from evaluations of the limiting binary system, Dwight and Mueller (21) found that at a high temperature, a continuous series of solid solutions existed throughout the ternary system. Increasing additions of zirconium and niobium were also found to stabilize the gamma phase to lower temperatures. Although niobium has a more potent effect in stabilizing the gamma phase, it was found that, in higher concentrations of niobium and zirconium, the gamma phase can be maintained as an equilibrium structure at room temperature over a significant portion of the terriary system. This investigation also indicated that the miscibility gaps observed in both the uranium-niobium and uranium-zirconium binary systems also exist in the ternary system; however, both miscibility gaps are closed with the addition of approximately 22.4 atom percent zirconium and 5.0 atom percent niobium. Figure 6 illustrates the effect of niobium and zirconium additions on closing the miscibility gaps and in stabilizing the sirigle-phase gamma structure in the ternary system.

As pointed out earlier, for both the limiting binary systems, rapid cooling from the gamma phase can produce various transitional phases. These specific transitional phases appeared to be a function of both the alloy compositions and cooling rates; however, efforts to characterize the influence of variations in the niobium and zirconium content on the transitional phases in the ternary system are incomplete. Using a limited number of alloys quenched at relatively slow and variable rates, Dwight and Mueller(21) determined a location for the $\alpha^{\prime} / \alpha^{\prime \prime}$ boundary and sketched in a bounded regiun uf gamma-o stability. The results of these efforts are illustrated in Figure 7.

In view of the limited number of samples used to determine these boundaries and the comparatively slow and sometimes interrupted quench rates used, additional efforts were needed to more precisely determine these boundaries at quench rates similar to those used 
in production heat-treating operations. These significant short comings in the available data concerning the ternary system prompted this study.

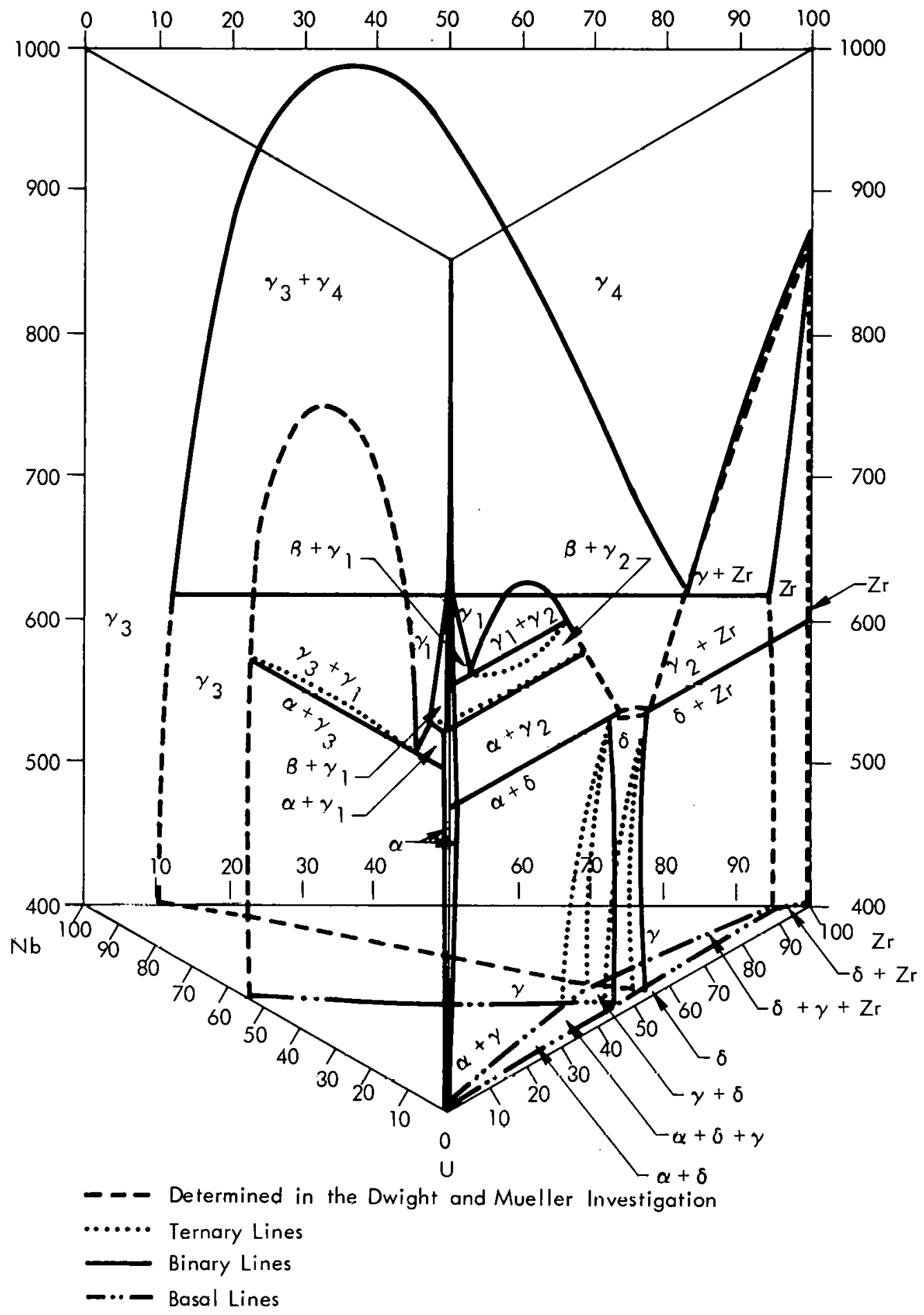

FIgUPe 5. IHREE-DIMENSIONAL SPACE DIAGRAM OF THE URANIUM-NIOBIUM-ZIRCONIUM SYSTEM. 


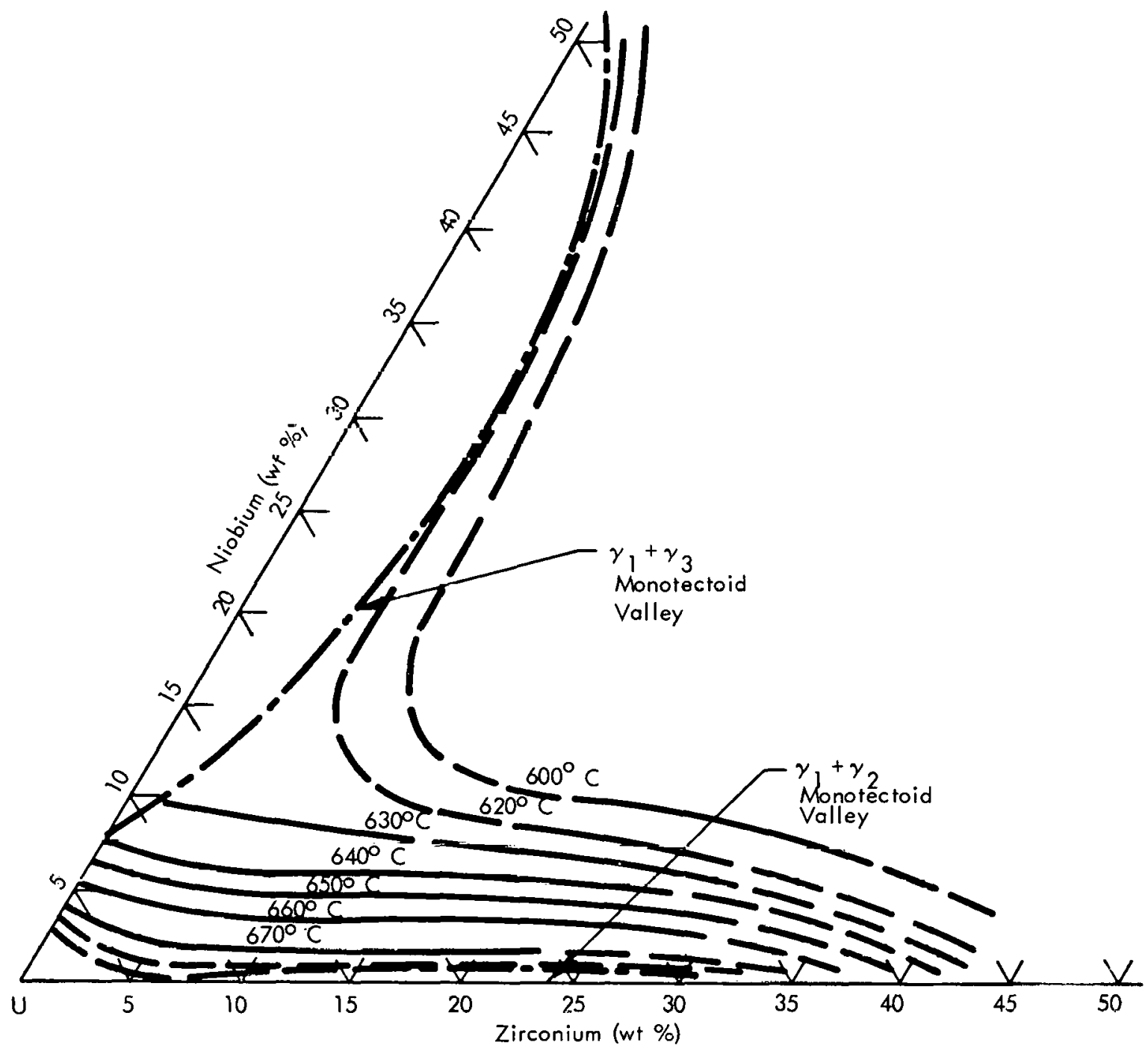

Figure 6. PROJECTION OF MONOTECTOID VALLEYS AND ISOTHERMAL LINES ONTO THE BASE PLANE OF THE URANIUM-NIOBIUM-ZIRCONIUM EQUILIBRIUM DIAGRAM.

Additional data have been obtained by Dean (22) and Giraud-Heraud and Guillaumirir (23) who have both studied the time-temperature transformation behavior of gamma-phase decomposition in a U-16.6 Nb-5.6 $\mathrm{Zr}$ alloy. Their work showed that rapid cooling of the high-temperature gamma phase produces a transitional gamma-s $\left(\gamma^{\mathbf{S}}\right)$ phase. (The gamma-s phase is not the retained high-temperature phase, but is a body-centered cubic structure having $X$-ray superlattice peaks thought to be the result of coordinated shift of the body-centered atoms. $(24)$ Subsequent low-temperature aging of the gamma-s structure produced the body-centered tetragonal transitional phase $\left(\gamma^{0}\right)$. Continued aging yielded the alpha double prime monoclinic phase.

Recently, interest has been directed toward understanding the mechanisms associated with the $\gamma^{\mathrm{s}} \rightarrow \gamma^{\mathrm{O}} \rightarrow \alpha^{\prime \prime}$ transformation. Using single-crystal $\mathrm{X}$-ray diffraction techniques on a U-16.6 Nb-5.6 $\mathrm{Zr}$ alloy, Yakel ${ }^{(24)}$ has suggested that Tangri's(25) description of the gamma-s and gamma-o phases in uranium-molybdenum alloys in terms of the chemical ordering of molybdenum is not a valid mechanism in the uranium-niobium-zirconium 
ternary system. Yakel suggested that the gamma-s structure may be thought of as being made up of eight unit cells of the original gamma structure in which the body-centered atoms have moved in $<100\rangle$ directions in a correlated manner. In addition, the body-centered tetragonal structure that is formed by low-temperature aging of the gamma-s structure is the result of continued movement of the body-centered atoms along specific [001] directions.

Electron microscope examination of samples of U-16.6 $\mathrm{Nb}-5.6 \mathrm{Zr}$ alloys aged at low temperatures by GiraudHeraud and Guillaumin (23)

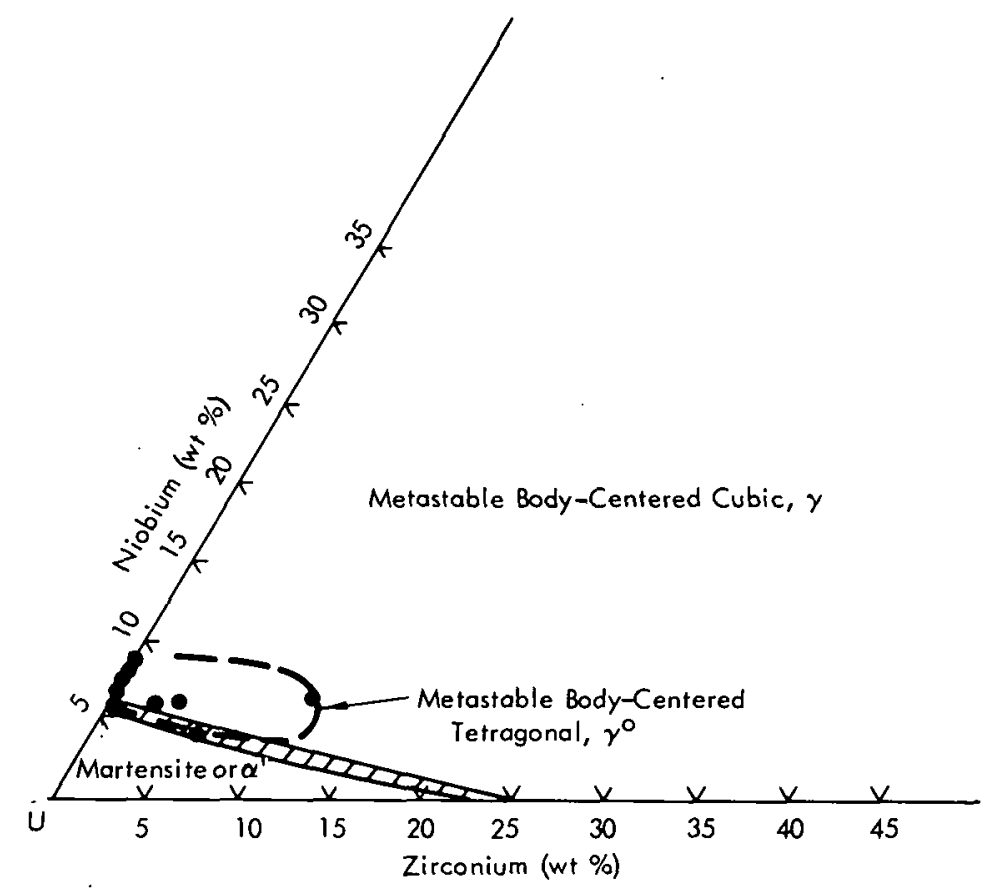

Figure 7. PROPOSED LOCATION OF THE $\alpha^{\prime} / \alpha^{\prime \prime}$ BOUNDARY AND THE $\gamma$ O REGION IN THE URANIUM-NIOBIUM-ZIRCONIUM TERNARY. (From Dwight and Mueller(21)) have revealed a striated structure which was interpreted as quasi-periodic strain fields or domains. These contrast effects are consistent with Yakel's hypothesis that the gamma-to-gamma-s phase changes are a nondiffusional process occurring by small correlated displacements of body-centered atoms. 


\section{EXPERIMENTAL PROCEDURE}

The material used in this investigation was prepared by consumable arc melting. Subsequently, the cast alloys were homogenized, hot upset forged, annealed, and cold rolled. Test coupons were obtained by sectioning one-inch-square pieces from each alloy plate. These coupons were finally gamma stabilized and water quenched. The crystal structures and lattice parameters of each annealed and quenched sample were determined by $X$-ray diffraction techniques. An in-depth description of the material preparation and experimental technique follows.

\section{MELTING AND SAMPLING}

The electrodes used in these melts were made up of approximately 16 , thin, rectangular strips fabricated from sheets of uranium, niobium, and zirconium. The uranlurr strips in all 20 electrodes were fabricated to a constant length, width, and thickness. The respective niobium and zirconium strips used in each electrode were fabricated to a flxed length arid thickness, while the width and number of each strip in an electrode were varied to obtain the desired alloy composition. Each electrode was subsequently melted into a two-inch-diameter by approximately four-inch-long ingot. Arc melting was performed in an NCR furnace using an average arc voltage and current of 28 volts and 1200 amperes, respectively. Melting operations were carried out under a slight partial pressure of helium to aid in initiating the arc. A uranium-16.6 atom percent niobium-5.6 atom percent zirconium (U-16.6 Nb-5.6 $\mathrm{Zr}$ ) disc was used as a striker to initiate the arc from each electrode. The bottom one-half inch of each ingot was removed to avoid possible alloy contamination. In addition, the top two inches of each ingot were removed to avoid the primary piping and porosity characteristic of the arc-melting process.

Each of the 20 ingots were analytically sampled for alloy content and metallic impurity level by parting a 20 -mil cross sectional chip sample from the surface produced by removing the hot top. In addition, five ingots were evaluated for gas content by removing a $1 / 8 \times 1 / 8$ $x$ 1-inch rectangular bar from the heat-treated coupon. A 1/8-inch-thick disc was removed from two ingots and each disc was later radiographed to determine the degree of alloy segregation developed on melting. A schematic drawing that illustrates the typical sampling and sectioning of these ingots is given in Figure 8.

\section{HOMOGENIZATION AND FORGING}

Twenty 2-inch-diameter by 1 1/4-inch-long billets were sectioned from each ingot and homogenized at $1000^{\circ} \mathrm{C}$ for 24 hours under a vacuum of $4.5 \times 10^{-5}$ torr. The billets were furnace cooled and metallographically inspected.

Following homogenization, each ingot was upset forged. Initial efforts to forge the first three billets produced significant edge cracking. These billets had been soaked under an argon purge for $11 / 2$ hours at $850^{\circ} \mathrm{C}$ and then forged under platens maintained at $315^{\circ} \mathrm{C}$. In order to reduce the edging cracking during subsequent forming, the remaining billets were soaked in an argon purge for two hours at $900^{\circ} \mathrm{C}$ and forged under $480^{\circ} \mathrm{C}$ platens.

After forging, a $1 \times 1 \times 1 / 4$-inch-thick coupon was sectioned from each billet. These coupons were subsequently cold rolled to a thickness of approximately $1 / 8$ inch. Each cold- 


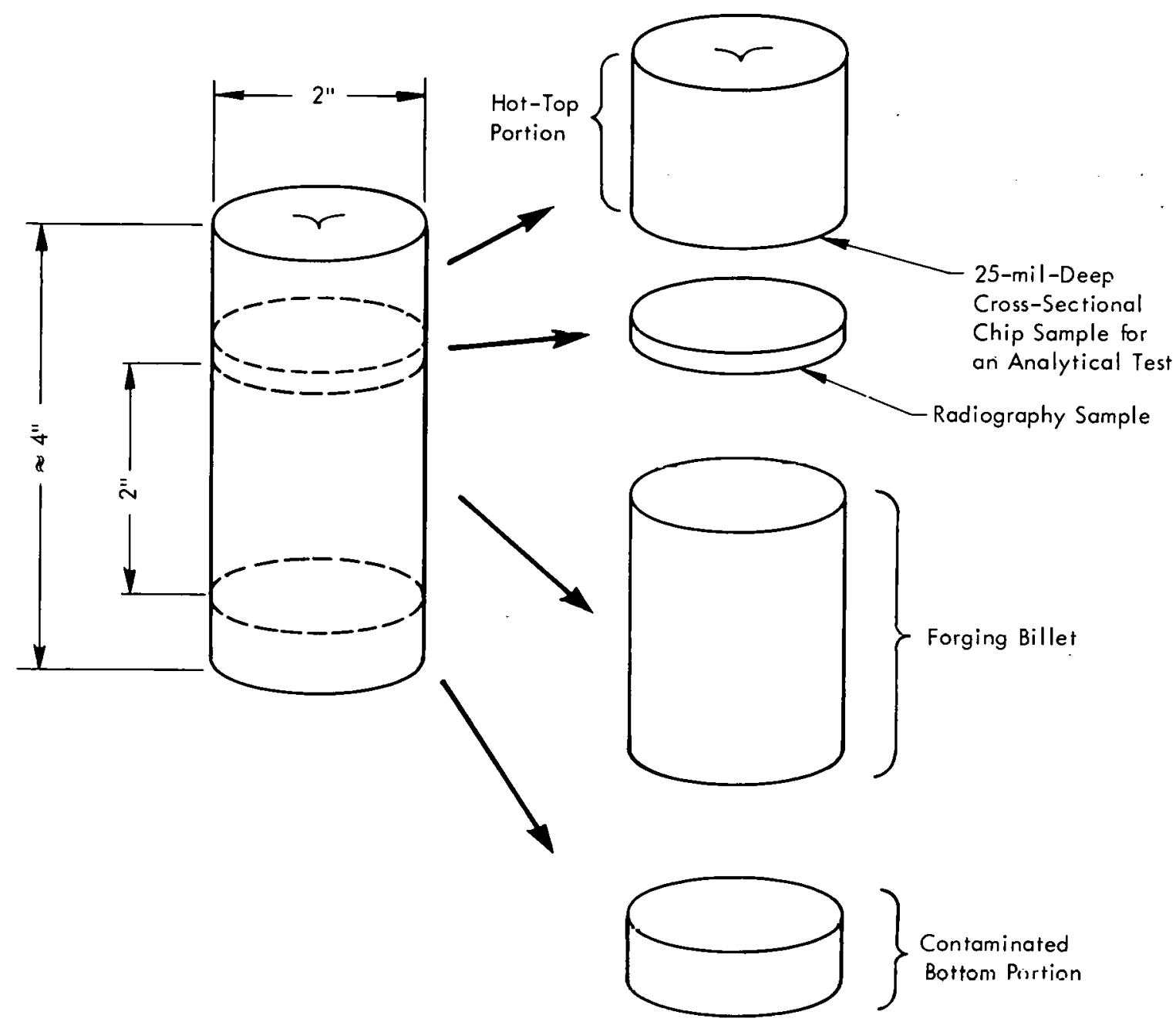

Figure 8. SAMPLING PLAN FOR THE ARC-MELT INGOTS USED IN THE EXPERIMENT.

rolled sample was then heat treated at $850^{\circ} \mathrm{C}$ in a vertical resistance furnace at a pressure of less than $1 \times 10^{-5}$ torr. After one hour at temperature, the furnace was back filled with argon and the samples immediately dropped into a high-volume spray of water. After characterization, Samples 6, 8, 11, 7, 9, 10, and 15 (Table 1) were reheat treated, in the manner just described, for one hour at $750^{\circ} \mathrm{C}$ followed by the water quench.

\section{METALLOGRAPHIC PREPARATION AND X-RAY DIFFRACTION TECHNIQUE}

Prior to X-ray diffraction evaluation, one surface of each $1 / 8$-inch-thick coupon was metallographically prepared. This preparation required grinding through 600 -grit silicon carbide paper followed by a sccondary polishing on a Syntron, using Linde $A$ abrasive in $5 \%$ chromic acid on metcloth. Final polishing was completed using Linde $B$ in $5 \%$ chromic acid on metcloth. Each specimen was electropolished in a $10 \%$ oxalic acid solution. Open-r.ircuit voltage for the electiupolishlng ranged trom two to four volts with exposure times varying from five to thirty seconds. At this point, the microstructure of each sample was examined. 
Table 1

METALLIC AND INTERSTITIAL IMPURITY LEVELS

\begin{tabular}{|c|c|c|c|c|c|c|c|c|}
\hline \multirow{2}{*}{$\begin{array}{l}\text { Sample } \\
\text { Number }\end{array}$} & \multicolumn{8}{|c|}{ Impurity (ppm) } \\
\hline & Carbon & Aluminum & Copper & Iron & Silicon & Oxygen & Nitrogen & Hydrogen \\
\hline 1 & 58 & 30 & 3 & 40 & 25 & & & \\
\hline$?$ & 35 & 10 & 4 & 10 & 60 & & & \\
\hline 3 & 66 & 6 & 5 & 45 & 35 & & & \\
\hline 4 & 56 & 8 & 5 & 60 & 40 & 50 & 15 & 2 \\
\hline 5 & 71 & 6 & 6 & 25 & 40 & & & \\
\hline 6 & 47 & 10 & 4 & 40 & 60 & & & \\
\hline 7 & 62 & 8 & 4 & 50 & 25 & & & \\
\hline 8 & 50 & 2 & 4 & 20 & 30 & 47 & 15 & 4 \\
\hline 9 & 62 & 2 & 4 & 25 & 25 & & & \\
\hline 10 & 53 & 6 & 6 & 46 & 40 & & & \\
\hline 11 & 52 & 2 & 5 & 50 & 25 & & & \\
\hline 12 & 104 & 2 & 10 & 25 & 25 & 05 & 20 & 1 \\
\hline 13 & 45 & 2 . & 4 & 40 & 10 & 62 & 20 & 3 \\
\hline 14 & 37 & 10 & 4 & 100 & 40 & & & \\
\hline 15 & 50 & 6 & 4 & 60 & 50 & & & \\
\hline 16 & 52 & 6 & 4 & 150 & 60 & 60 & 20 & 4 \\
\hline 17 & 54 & 8 & 4 & 50 & 40 & & & \\
\hline 18 & 59 & 20 & 5 & 45 & 35 & & & \\
\hline 19 & 57 & 10 & 4 & 100 & 50 & & & \\
\hline 20 & 52 & 6 & 4 & 200 & 60 & & & \\
\hline
\end{tabular}

$X$-ray diffraction data were obtained using nickel-filtered copper $X$ radiation and a conventional Norelco diffractometer. Diffraction beams were scanned at a rate of $1 / 8$ degree per minute over a two-theta range of 25 to 120 degrees. Intensity measurements of the diffracted beams were obtained from a gas-type proportional counter after being screened by a pyrolytic graphite monochromator to reduce background scatter. Data gathering was automated by amplifying the proportional counter signal and subsequently passing it through a single-channel-analyzer discriminating circuit and collected by a digital ratemeter. The ratemeter effectively summed and averaged the proportional counter output over a six-second period, or 0.0125 two theta, before printing out this information on both paper and paper tape. By having synchronized the ratemeter and diffractometer, the paper-tape output could be used as computer input to obtain plots of intensity (counts per second) versus two theta.

Apparent lattice parameters for the cubic structures were calculated for all diffraction peaks from measurements of angular locations of the peaks obtained from the plots. Corrections for sample displacement from the diffractometer axis and other systematic errors were accounted for by performing a linear least square fit of the lattice parameters of each peak of a sample to the function $\operatorname{ctn} \theta \cos \theta$ and extrapolating to $\operatorname{ctn} \theta \cos \theta=0$. In addition, corrections for diffractometer misalignment were made by comparison of diffraction data obtained from a well-annealed silicon standard with handbook values.

Lattice parameters for the monoclinic materials were obtained by determining the peak's two-theta locations using computer techniques described elsewhere. (26) These peaks were arbitrarily indexed, and an initial solution for the monoclinic lattice parameter was made using a polynominal least-square technique. Reiteration of the, indexing of individual peaks was made until a lattice-parameter solution was obtained having a maximum precision. 
Microhardness tests were performed on the sample coupons following the X-ray diffraction evaluation of each respective alloy. Diamond pyramid hardness (DPH) values were obtained from the as-polished surface of each sample using a Tukon microhardness tester with a 1000-gram load. Twelve readings were randomly taken on each sample, and the values reported are the average of these readings. 


\section{RESULTS AND DISCUSSION}

\section{GENERAL INGOT CHARACTERIZATION}

Tahle 1 summarizes the impurity levels of each of the ingots used in this experiment. A review of this table indicates that a summation of the average levels of carbon, copper, Irun, and silicon found in each of these 20 alloys is $166.3 \mathrm{ppm}$. The maximum total metallic impurity level observed in any one ingot was $322 \mathrm{ppm}$ and was observed in Sample 20. In addition, results of gas analyses taken from five alloys are also listed in Table 1 and suggest that a high level of purity was also obtained with regard to oxygen, nitrogen, and hydrogen.

The allov content of each of the ingots was determlried frum d 0.020 -ineh cross scotional lathe cut. This technique was used to "average out" the ettects of microscoplc seyr egation patterns. Results of these analyses are listed in Table 2. In order to characterize the macroscopic segregation associated with these samples, a radiograph was made of a disc taken from the cross section of two representative ingots having either high or low total alloy content. Figure 9 is a positive print of the radiograph taken from the U-12.1 Nb-16.2 $\mathrm{Zr}$ alloy. This radiograph indicates that radial segregation within the ingot is minimal with respect to previous experience with arc melts of uranium alloys. As a result of using the homogenization procedure outlined by Dean $(22)$ to minimize microscopic segregation and the low level of macroscopic segregation observed in the radiograph (Figure 9), a high degree of alloy uniformity is thought to exist within each ingot in this experiment.

\section{RECRYSTALLIZATION}

Initial $X$-ray diffraction patterns obtained from material heat treated at $850^{\circ} \mathrm{C}$ and water quenched following the hot upset forging and homogenizing steps were found to be broad and diffuse. In this condition, the accuracy of the BCC lattice parameter measurcments was reduced and the indexing of the monoclinic peaks was impractical. Metallographic examination of this material revealed an abnormal microstructure in 15 of the 20 samples. Eleven of these 15 specimens were found to have areas of large, clean, equiaxed grains and varying areas of a dark, unresolvable structure (Figure 10). Reduction in the ctching time revealed that the dark areas were made up of grains having a complex substructure, as shown in Figure 11. Although significant variations in the percentage of grains possessing this complex substructure could be observed in these 11 samples, no statistically significant relationships with solute content could be determined. The remaining four samples in this group of 15 were found to have poorly defined grain boundaries containing a trace of substructure (Figure 12).

In view of the broad X-ray diffraction peaks, microstructure, and previous experience with dilute alloys of uranlum-niubiuri-zirconium, the 20 specimens were assumed to be incompletely recrystallized. In order to correct this situation, each sample was reduced in thickness approximately $50 \%$ by cold rolling prior to a subsequent vacuum heat treatment at $850^{\circ} \mathrm{C}$ for one hour followed by water quenching. Samples treated in this manner had well-defined grains which were free of substructure (Figure 13). Subsequent $X$-ray diffraction studies of the material yielded sharp and distinct patterns. 


\section{CHARACTERIZATION OF CUBIC LATTICE PARAMETERS}

Of the 20 test coupons quenched from $850^{\circ} \mathrm{C}$, nine were found to have BCC lattice symmetry and to be free of superlattice peaks. Lattice parameters for these samples ranged from 3.459 to $3.494 \AA$. Pooling these data with the lattice parameters of the four samples found to have a gamma-s structure (also BCC) allowed a statistical analysis aimed at correlating the cubic lattice parameters to the alloy content. This analysis was carried out using a stepwise multiple linear regression computer technique. This method allowed the step-wise correlation of the BCC lattice parameters of each alloy to its respective composition in atom percent expressed in the following terms: $\mathrm{Nb}, \mathrm{Nb}^{2}, \mathrm{Nb}^{3}, \mathrm{Zr}, \mathrm{Zr}^{2}, \mathrm{Zr}^{3}$, $\mathrm{Nb} / \mathrm{Zr}$, and $\mathrm{Nb} \times \mathrm{Zr}$. The analysis revealed that a first-order polynominal expression with zirconium would account for approximately $90 \%$ of the variation in the observed BCC lattice parameters. The addition of a niobium term to this polynominal accounted for an additional $8 \%$ of the variation in the data. No other terms were found to be of statistical significance. The resulting polynominal expression is:

Table 2

ALLOY CONTENT, LATTICE PARAMETERS, AND MICROHARDNESS OF QUENCHED SAMPLES

\begin{tabular}{|c|c|c|c|c|c|c|c|c|c|}
\hline \multirow{2}{*}{$\begin{array}{l}\text { Sample } \\
\text { Number }\end{array}$} & \multicolumn{3}{|c|}{$\begin{array}{c}\text { Sample Chemistry } \\
\text { (at \%) }\end{array}$} & \multirow{2}{*}{$\begin{array}{l}\text { Crystal } \\
\text { Structure }\end{array}$} & \multicolumn{3}{|c|}{ Lattice Parameter $(\AA)$} & \multirow{2}{*}{$\begin{array}{c}\hat{\gamma} \\
\text { (degrees) }\end{array}$} & \multirow{2}{*}{$\begin{array}{l}\text { Microhardness } \\
\text { (DPH) }\end{array}$} \\
\hline & $\mathrm{U}$ & $\mathrm{Nb}$ & $\mathrm{Zr}$ & & a & b & c & & \\
\hline \multicolumn{10}{|c|}{ Samples Quenched from $850^{\circ} \mathrm{C}$} \\
\hline 1 & 67.9 & 11.3 & 20.8 & $\alpha^{\prime \prime}$ & 2.929 & 5.824 & 5.031 & 91.4 & 233 \\
\hline 2 & 84.2 & 11.8 & 4.0 & $\alpha^{\prime \prime}$ & 2.919 & 5.784 & 4.996 & 92.2 & 156 \\
\hline 3 & 80.8 & 5.9 & 13.3 & $\alpha^{\prime \prime}$ & 2.930 & 5.800 & 5.013 & 92.4 & 191 \\
\hline 4 & 82.7 & 10.5 & 6.8 & $\alpha^{\prime \prime}$ & 2.927 & 5.794 & 5.007 & 92.5 & 152 \\
\hline 5 & 84.0 & 13.9 & 2.1 & $\alpha^{\prime \prime}$ & 2.942 & 5.748 & 4.971 & 94.0 & 118 \\
\hline 6 & 81.7 & 13.7 & 4.6 & $\alpha^{\prime \prime}$ & 2.353 & 5.756 & 4.980 & 94.1 & 142 \\
\hline 7 & 74.2 & 8.4 & 17.4 & $\gamma^{0}+\alpha^{\prime \prime}$ & $\left\{\begin{array}{l}2.977 \\
3.497\end{array}\right.$ & 5.981 & $\begin{array}{l}4.980 \\
3.488\end{array}$ & $95.2\}$ & 238 \\
\hline 8 & 80.7 & 17.0 & 2.3 & $\gamma^{\circ}$ & 3.494 & & 3.438 & & 194 \\
\hline 9 & 77.2 & 17.4 & 5.4 & $\gamma^{s}$ & 3.463 & & & & 241 \\
\hline 10 & 76.7 & 14.5 & 8.7 & $\gamma^{s}$ & 3.472 & & & & 209 \\
\hline 11 & 74.5 & 12.5 & 13.0 & $\gamma^{s}$ & 3.477 & & & & 241 \\
\hline 12 & 77.2 & 20.5 & 2.2 & $\gamma^{s}$ & 3.459 & & & & 275 \\
\hline 13 & 73.1 & 20.8 & 6.1 & $\gamma$ & 3.460 & & & & 290 \\
\hline 14 & 72.9 & 16.4 & 10.6 & $\gamma$ & 3.467 & & & & 286 \\
\hline 15 & 71.8 & 12.1 & 16.2 & $\gamma$ & 3.487 & & & & 275 \\
\hline 16 & 67.9 & 11.3 & 20.8 & $\gamma$ & 3.491 & & & & 292 \\
\hline 17 & 68.5 & 19.4 & 12.2 & $\gamma$ & 3.470 & & & & 302 \\
\hline 18 & 69.2 & 10.0 & 20.8 & $\gamma$ & 3.495 & & & & 297 \\
\hline 19 & 69.1 & 15.6 & 15.0 & $\gamma$ & 3.477 & & & & 288 \\
\hline 20 & 65.8 & 11.5 & 22.7 & $\gamma$ & 3.495 & & & & 289 \\
\hline \multicolumn{10}{|c|}{ Samples Quenched from $750^{\circ} \mathrm{C}$} \\
\hline 6 & 81.7 & 13.7 & 4.6 & $\gamma$ & 2.931 & 5.739 & 4.978 & 94.0 & \\
\hline 8 & 80.7 & 17.0 & 2.3 & $\gamma^{0}$ & 3.495 & & 3.423 & & \\
\hline 11 & 74.5 & 12.5 & 13.0 & $\gamma^{0}$ & 3.502 & & 3.494 & & \\
\hline 7 & 74.2 & 8.4 & 17.4 & $\gamma^{0}+\alpha^{\prime \prime}$ & & & & & \\
\hline 9 & 77.2 & 17.4 & 5.4 & $\gamma^{\mathrm{S}}$ & 3.463 & & & & \\
\hline 10 & 76.7 & 11.5 & 8.7 & $\gamma^{5}$ & 3.472 & & & & \\
\hline 15 & 71.8 & 12.1 & 16.2 & $\gamma$ & 3.488 & & & & \\
\hline
\end{tabular}




$$
\begin{aligned}
& A_{0}=K_{1}+K_{2} \mathrm{Nb}+K_{3} Z r, \\
& K_{1}=3.479 \pm 0.0055,(b) \\
& K_{2}=-13.0 \pm 7.1 \times 10^{-4}, \text { and } \\
& K_{3}=12.9 \pm 4.7 \times 10^{-4},
\end{aligned}
$$

while Figure 14 demonstrates, graphically, the fit between this expression and the experimental results from this study. Solution of this polynominal equation for concentrations of niobium and zirconium approaching zero suggests that the $\mathrm{K}_{1}$ term is an estimate of the room-temperature BCC lattice parameter of pure uranium $\left(A_{O}=3.479 \pm 0.055 \AA\right)$. I his value is in close agreement with a $3.474 \pm 0.005 \AA$ estimate made by Wilson and Rundle, (27) based on an extrapolation of the lattice constants of the metastable gamma phases found in uranium alloys ranging in composition from 17.3 to 31.2 atom percent molybdenum.

Furthermore, solution of this equation for $100 \%$ niobium and zirconium yields an apparent BCC lattice parameter for elemental niobium and zirconium. Multiplying these values by $\sqrt{3 / 2}$ yields 2.90 and $3.12 \AA$, respectively, which are the approximate nearest neighbor spacings of niobium and zirconium in a BCC lattice. This linear dependence of lattice spacing with composition has been observed previously in salts and metallic solutions, and generally is reterred to as Vegard's law. (28)

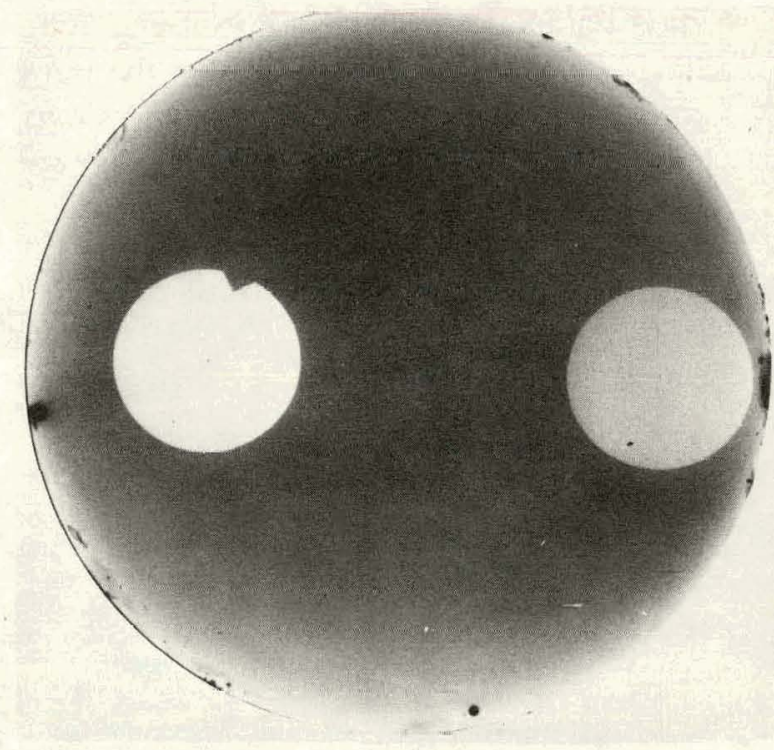

157562

Figure 9. POSITIVE PRINT OF A RADIOGRAPH OF A ONE-EIGHTH-INCH-THICK CROSS-SECTIONAL DISC FROM AN ARC-MELT INGOT. (Ingot has the Following Composition: Uranium-12.1 at \% Niobium-16.2 at \% Zirconium) Carrying this evaluation further, it should be noted that the magnitude and sign of $\mathrm{K}_{2}$ and $\mathrm{K}_{3}$ are in agreement with size-factor considerations. A comparison of the reported nearest-neighbor spacing for niobium and zirconium to the nearest-neighbor distance for $\mathrm{BCC}$ uranium, derived from the $\mathrm{K}_{1}$ term in Equation 1, suggests that the niobium atom is approximately $4.9 \%$ smaller than uranium, while the zirconium is approximately $5.8 \%$ larger than uranium. This observation suggests that the magnitude of the respective Ks should be approximately equal, but opposite in sign. Both of these predictions were observed in Equation 1.

(b) All limits of error in this thesis are with $90 \%$ confidence, unless otherwise noted. 


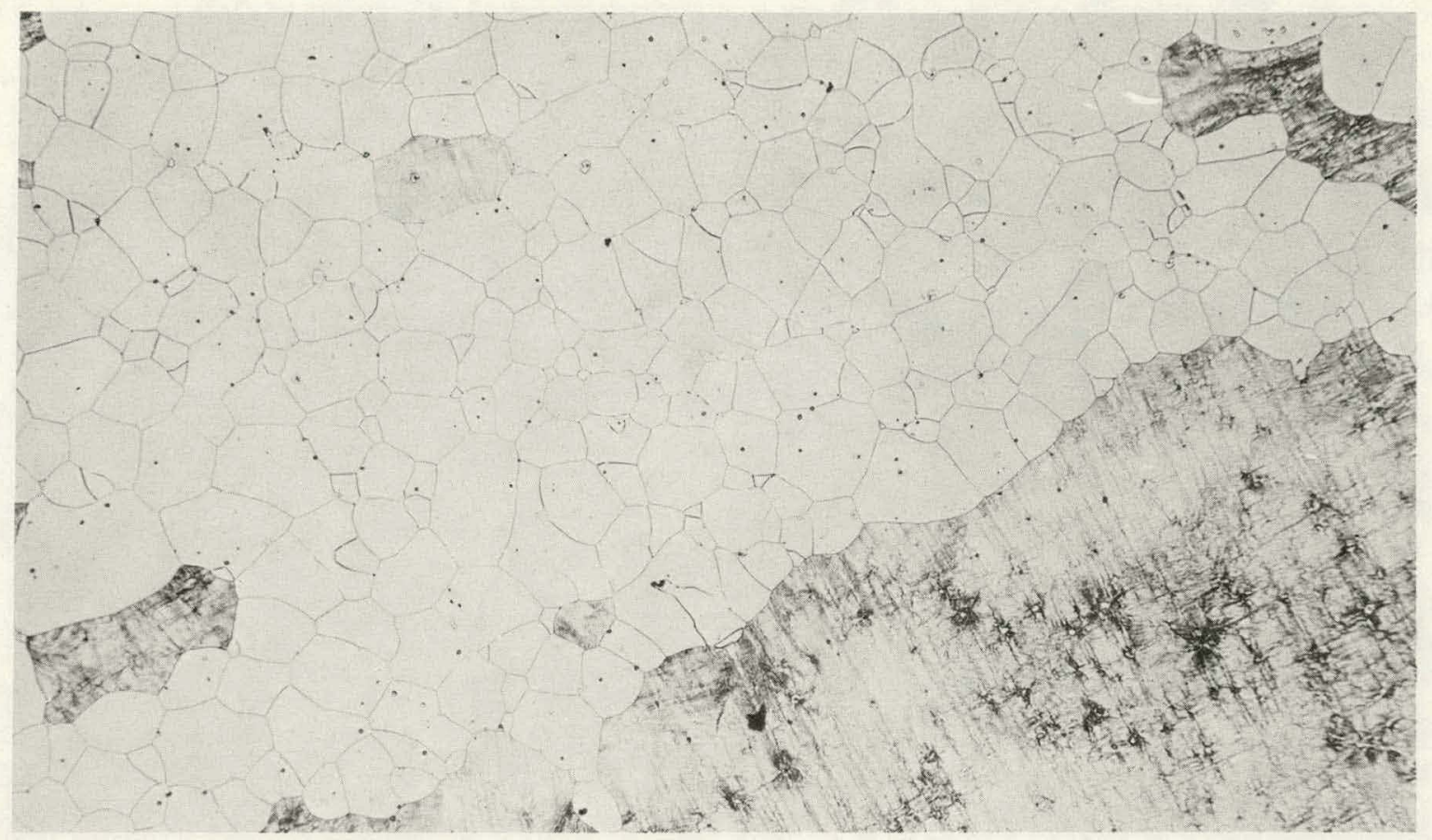

Figure 10. PHOTOMICROGRAPH OF A URANIUM-20.5 ATOM PERCENT NIOBIUM-2.5 ATOM PERCENT ZIRCONIUM ALLOY THAT EXHIBITS A COMPLEX MICROSTRUCTURE AFTER A FABRICATION CYCLE CONSISTING OF HOT UPSET FORGING, HOMOGENIZING, AND VACUUM ANNEALING, FOLLOWED BY WATER QUENCHING. (Note the Dark, Partially Recrystallized Areas; Oxalic Acid Etchant; 100X)

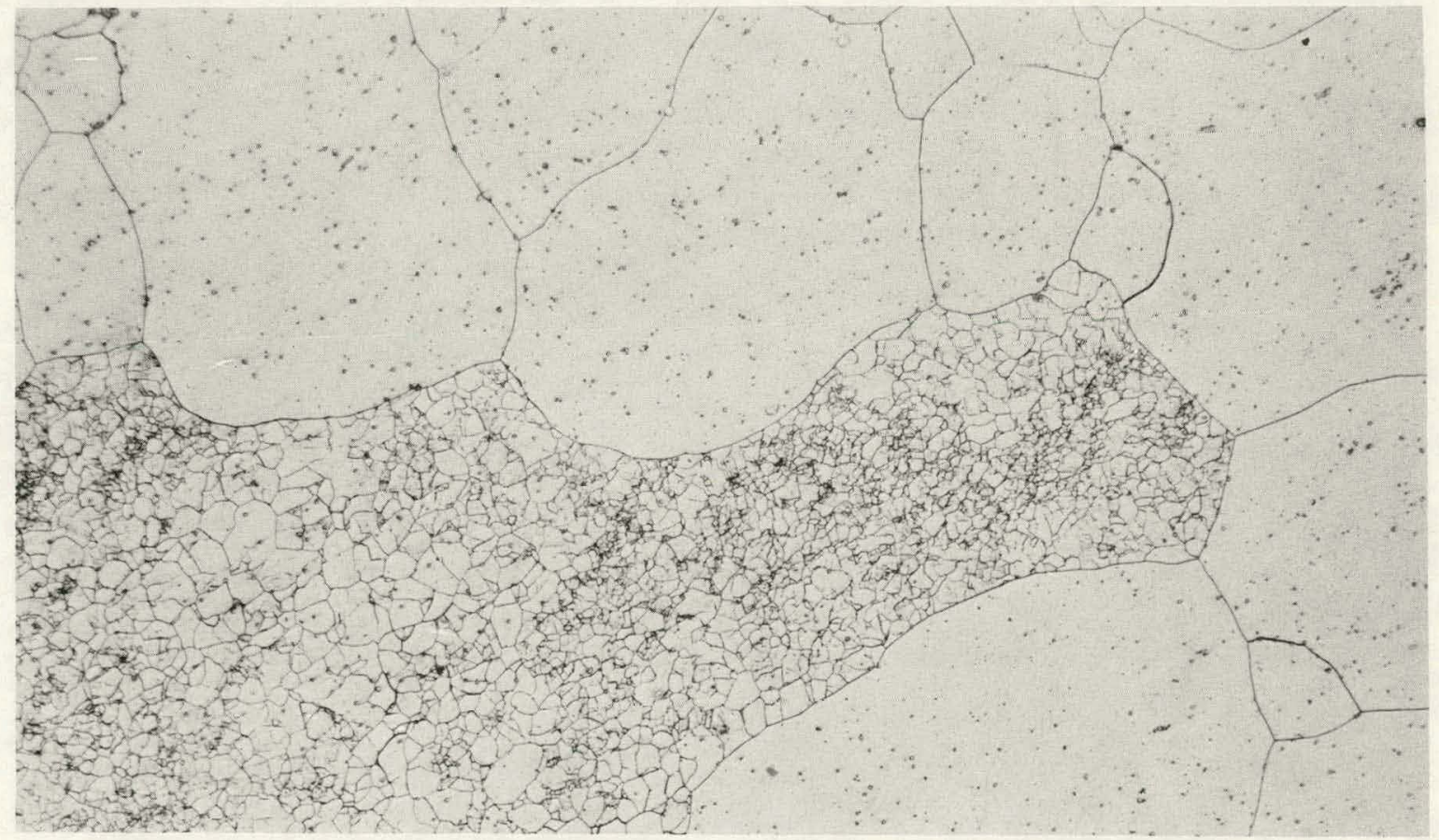

Figure 11. PHOTOMICROGRAPH OF A URANIUM-5.9 ATOM PERCENT NIOBIUM-13.3 ATOM PERCENT ZIRCONIUM ALLOY THAT EXHIBITS A COMPLEX MICROSTRUCTURE AFTER A FABRICATION CYCLE CONSISTING OF HOT UPSET FORGING, HOMOGENIZING, AND VACUUM ANNEALING, FOLLOWED BY WATER QUENCHING. (Note the Subgrain Structure; Oxalic Acid Etchant; 100X) 


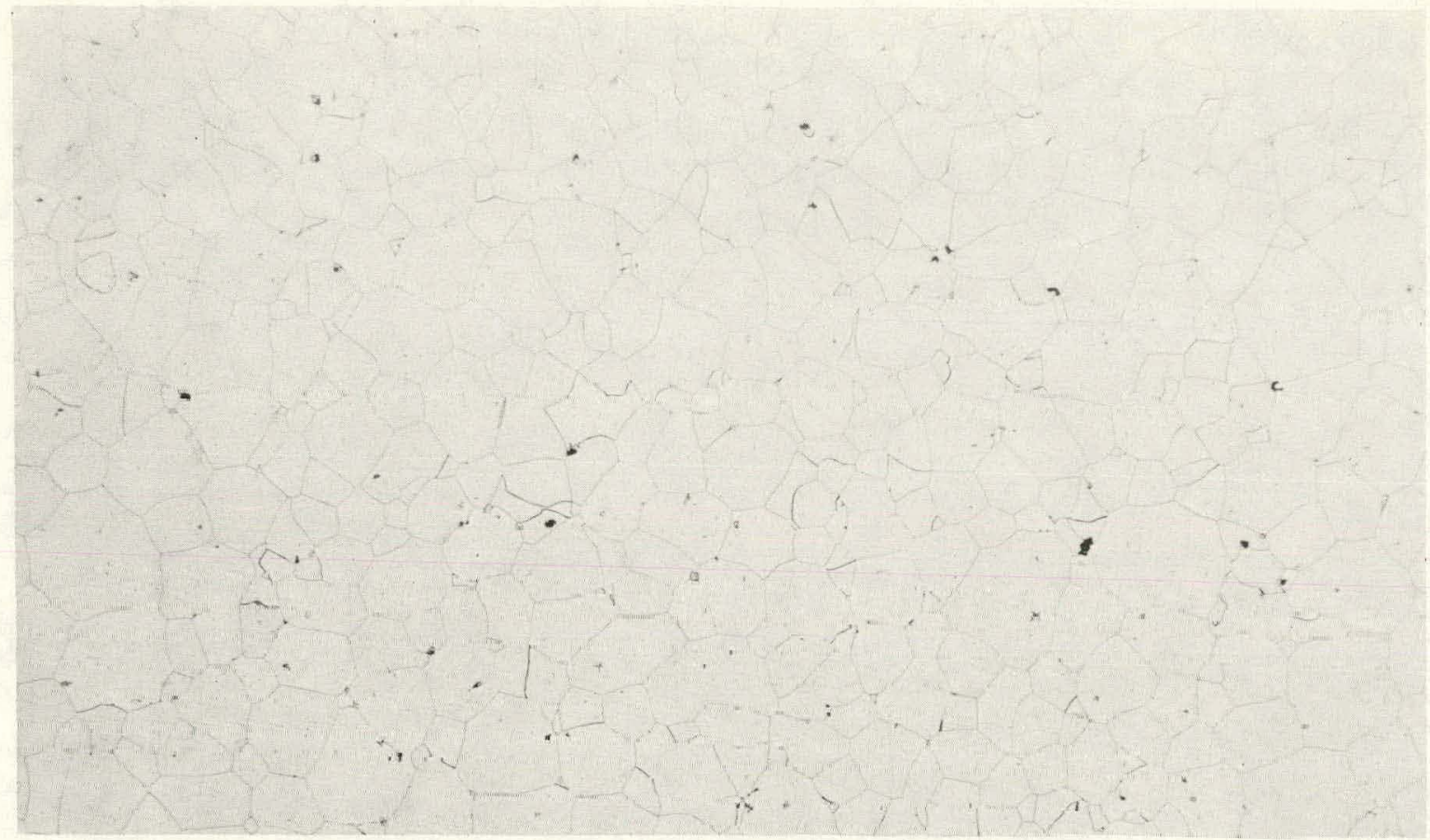

Figure 12. PHOTOMICROGRAPH OF A URANIUM-15.6 ATOM PERCENT NIOBIUM-15.1 ATOM PERCENT ZIRCONIUM ALLOY THAT EXHIBITS A COMPLEX MICROSTRUCTURE AFTER A FABRICATION CYCLE CONSISTING OF HOT UPSET FORGING, HOMOGENIZING, AND VACUUM ANNEALING, FOLLOWED BY WATER QUENCHING. (Note the Poorly Defined Grain Boundaries; Oxalic Acid Etchant; 100X)

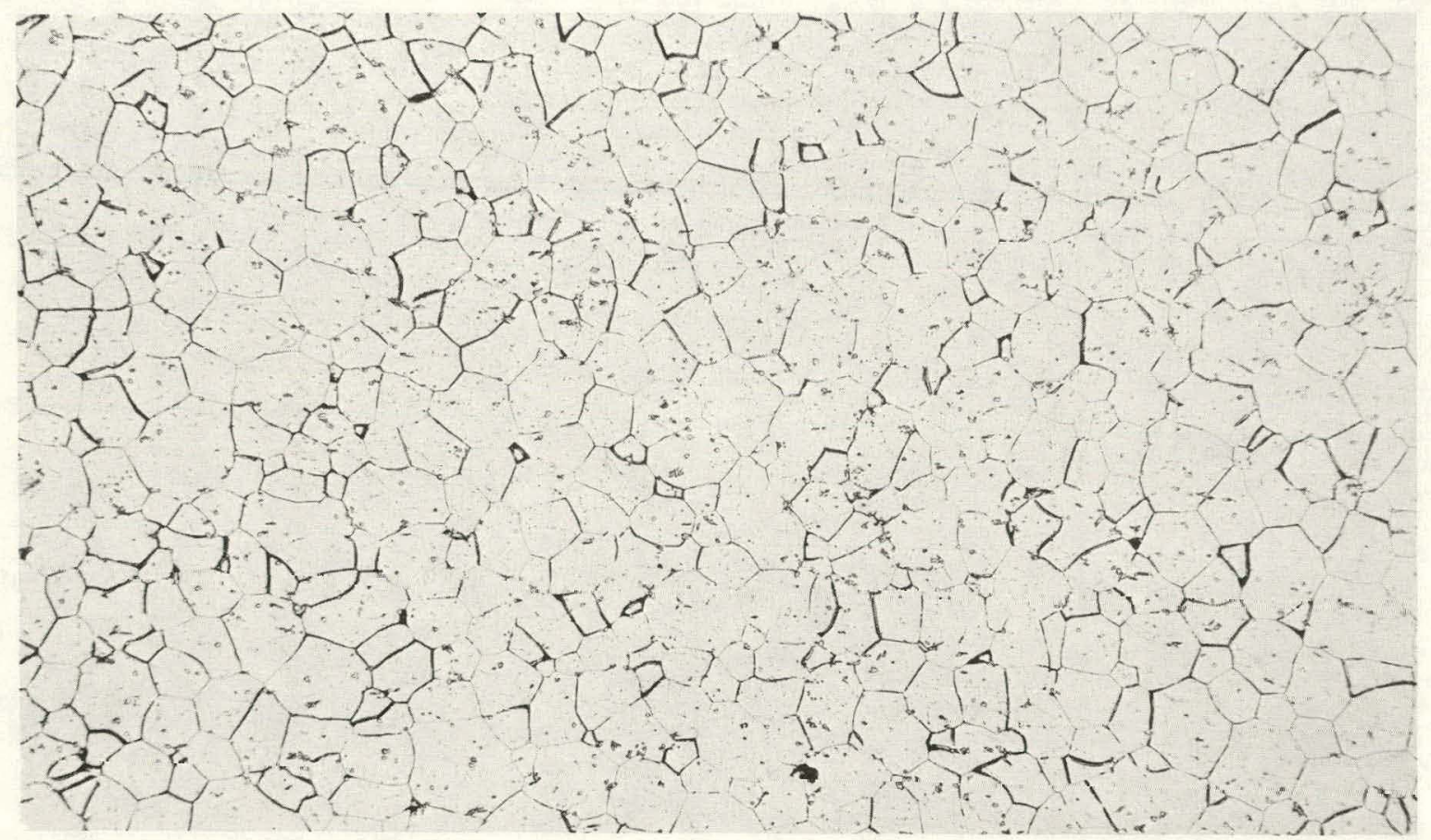

Figure 13. PHOTOMICROGRAPH OF A URANIUM-17.4 ATOM PERCENT NIOBIUM-5.4 ATOM PERCENT ZIRCONIUM ALLOY THAT EXHIBITS A TYPICAL MICROSTRUCTURE AFTER A FABRICATION CYCLE CONSISTING OF HOT UPSET FORGING, HOMOGENIZATION, AND COLD ROLLED AND VACUUM ANNEALING, FOLLOWED BY WATER QUENCHING. (Note the Well-Defined Grain Boundaries and Lack of Substructure; Oxalic Acid Etchant; 100X) 


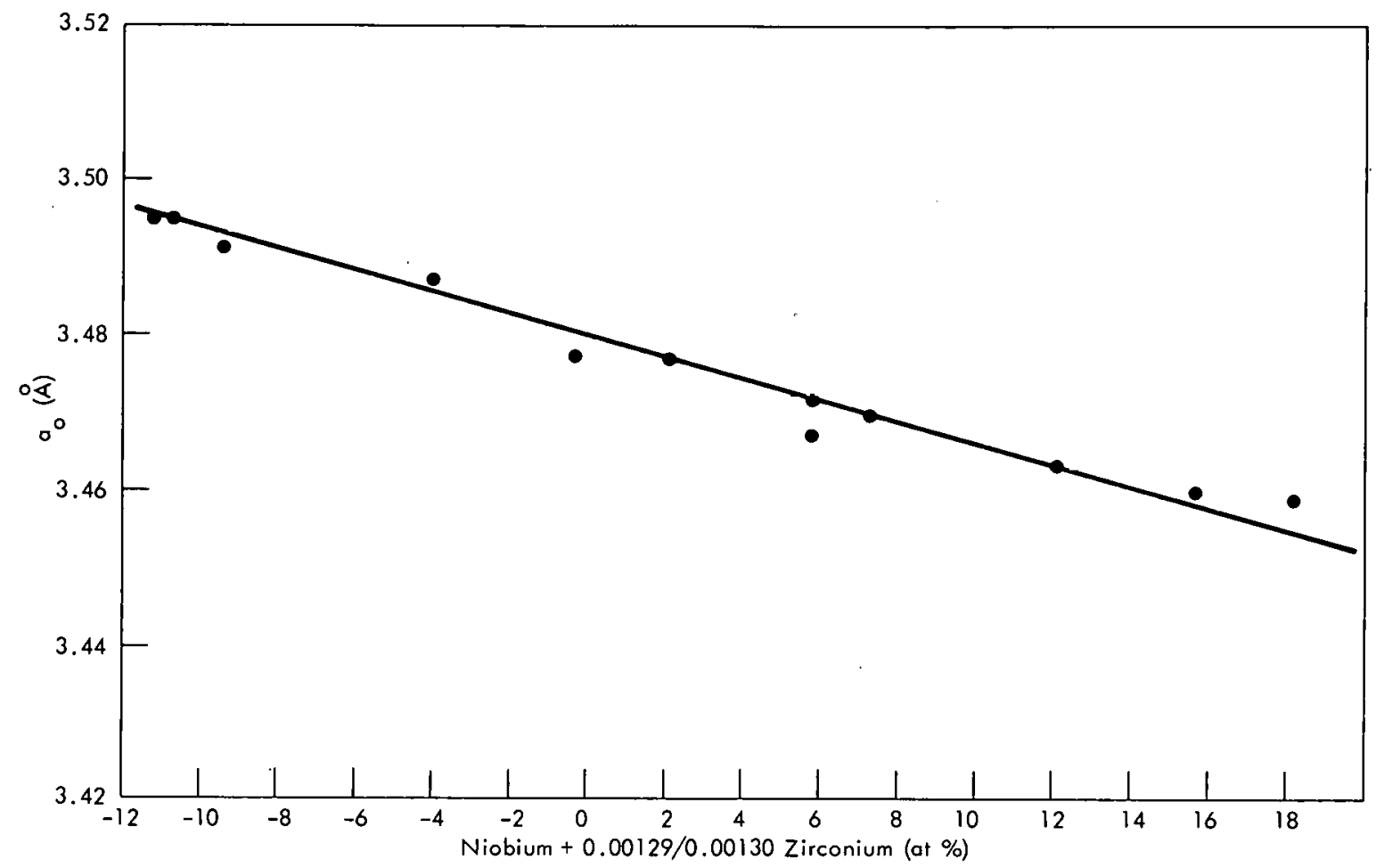

Figure 14. VARIATION OF THE BCC LATTICE PARAMETER AS A FUNCTION OF THE NIOBIUM AND ZIRCONIUM CONTENTS.

\section{GAMMA-S AND GAMMA-O STRUCTURES}

Only four of the 20 samples quenclied from $850^{\circ} \mathrm{C}$ were found to have the superlattice peaks that characterize the gamma-s structure. The diffraction intensity versus the two-theta plot for the U-17.4 Nb-5.4 $\mathrm{Zr}$ alloy is depicted in Figure 15 and is representative of the diffraction scans of the other gamma-s alloys. In all four test coupons, the superlattice peak at the lowest two-theta value was found to bc at least $40 \%$ greater than background. A review of the diffraction scans of samples of higher alloy content showed no resolvable superlattice peaks.

Tangri (25) has proposed that the superlattice peaks that characterize the gamma-s structures are the result of chemical ordering of atoms of a different scattering power. Recently, Yakel(24) has suggested that the superlattice peaks are the result of small displacements of the body-centered atoms of the original BCC lattice along the $\langle 100\rangle$ gamma directions. In order to prove his point, Yakel $(24)$ calculated the expected location and intensity of the superlattice peaks for his displaced structure and Tangri's $(25)$ chemical order lattice. These locations are indicated as $D$ and $O$, respectively, in Figure 15. A comparison of the two-theta positions of the superlattice peaks observed in this and other samples with Yakel's ${ }^{(24)}$ calculations support the atomic displacement model.

Quenching from $850^{\circ} \mathrm{C}$ produced a detectable body-centered tetragonal structure only in the $\mathrm{U}-17.0 \mathrm{Nb}-2.3 \mathrm{Zr}$ alloy. This structure was estimated to have a c/a ratio of 0.696 with 
$a=4.941 \AA$. (c) Again, a comparison of the location and relative intensities of the superlattice peaks associated with this sample (Figure 16) with the location and intensities calculated by Yakel(24) for a chemically ordered structure and displacement lattice reinforce Yakel's $(24)$ theory that the superlattice peaks associated with the gamma-o material are also the results of atomic displacement of the body-centered atoms along the [001] gamma directions.

The characteristic microstructure of the gamma and gamma-s materials is illustrated in Figure 13, while the microstructure of the gamma-o material is shown in Figure 17. A review of the microstructure of the varlous sairiples $\left(\gamma, \gamma^{s}, \gamma^{0}\right.$, and $\left.\alpha^{\prime \prime}\right)$ does reveal a varying number of inclusions which previous studies on this alloy system identified as complex niobium and zirconium carbides. Therefore, in noting that no grain-boundary coarsening, twinning, or other unusual microstructural anomalies were observed in the microstructure of the various gamma samples $\left(\gamma, \gamma^{\mathrm{s}}\right.$, or $\left.\gamma^{\circ}\right)$ suggest that the $\gamma \rightarrow \gamma^{\mathrm{s}} \rightarrow \gamma^{\circ}$ transformation cannot be detected by the optical microscope. Furthermore, in the U-17.0 Nb-2.3 $\mathrm{Zr}$ alloy, note, specifically, that no banding or grain deformation was ohserved. Therefore, following the nomenclature proposed by Lehman and Hill, (29) this sample was not classified as $\gamma_{d}^{O}$.

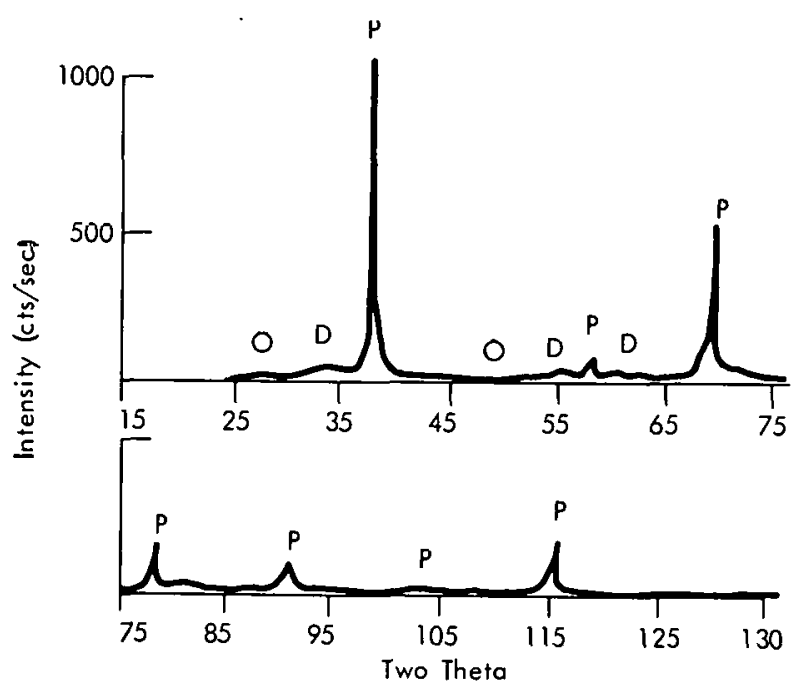

Figure 15. DEPICTION OF THE DIFFRACTION INTENSITIES VERSUS TWO THETA FOR A URANIUM-17.4 ATOM PERCENT NIOBIUM-5.4 ATOM PERCENT ZIRCONIUM $A L L O Y$. (" $O$ " and " $D$ " Denote the Location of the Expected Superlattice Peaks, Assuming Tangri's Hypothesis of Chemical Urdering arid Yakel's Proposod Atomir: Displacement Mechanism, Rospoctively: "p" Identifies the Location of the Primary Peaks Associated with the BCC Structure)

\section{ALPHA-DOUBLE-PRIME STRUCTURE}

Quenching the 20 various alluys from $850^{\circ} \mathrm{C}$ resulted in X-ray diffraction data for six samples which could be successfully indexed on the basis of a monoclinic structure. The microstructure of these six samples rcvealed a faint acicular, or Widmanstatten, structure. Figures 18 and 19 Illustlate this microstructure in the U-5.9 Nb-13.3 $\mathrm{Zr}$ alloy. A similar microstructure has been reported in quenched samples of dilute uranium-niobium alloys dnid isothermally transformed uranium-niobium-zirconium ternary alloys. (22)

(c) These parameters are based on the primitive cell proposed by Yakel: $a_{\gamma}{ }^{0} \cong \sqrt{2} \mathrm{a}_{\gamma}$ and $\mathrm{c}_{\gamma}{ }^{0} \cong \mathrm{a}_{\gamma}$. 
A review of the lattice parameters associated with each of these six samples indicated little variation in the $\mathrm{a}, \mathrm{b}$, and c parameters; however, $\hat{\gamma}$, the monoclinic angle, ranged from 91.4 to 94.1 degrees. Efforts to correlate this variation in the monoclinic angle with the alloy content were carried out using the stepwise multilinear regression technique noted previously. Similar to the preceding case, the only statistically significant terms were niobium and zirconium. The resulting expression is:

$$
\begin{aligned}
& \hat{\gamma}=K_{1}+K_{2} \mathrm{Nb}+K_{3} \mathrm{Zr}, \\
& K_{1}=82.0 \pm 0.37, \\
& K_{2}=0.77 \pm 0.50, \text { and } \\
& K_{3}=0.35 \pm 0.34 .
\end{aligned}
$$

while Figure 20 demonstrates, graphically, the fit between this expression and the experimental results from this study. In order to better understand this relation, the theoretical limiting values of the monoclinic angle should be determined. From an examination of the atom sites on the (110) plane of a BCC lattice [Figure 21(a)], a monoclinic unit cell can be visualized. The outline of this monoclinic cell projected on its (001) plane is shown by dark lines in Figure 21(a). Assuming a BCC lattice parameter of $3.450 \AA$, the dimensions of the apparent monoclinic cell are: $a=2.98 \AA, b=5.72 \AA, c=4.90 \AA$, and $\hat{\gamma}=100^{\circ}$. where the value of $\hat{\gamma}=100^{\circ}$ is independent of the BCC lattice parameter.

Progressive amounts of shear along the $(\overline{1} 11)_{\gamma}$ directions will destroy the BCC lattice; however, the monoclinic symmetry will remain as the monoclinic angle parameter continuously decreases. When shear of the original BCC lattice has reduced the monoclinic angle to 90 degrees [accompanied by small displacements along the (001) directions], this atomic arrangement becomes a HCP plane [Figure 21(b)]. From this atomic arrangement, an orthorhombic lattice can be described, outlined by dark lines in Figure 21 (b). Therefore, the expected limiting values of the monoclinic angle are 90 and 100 degrees. At these monoclinic angle values, the resulting atomic arrangements are more accurately described in terms of either orthorhombic or BCC crystal symmetry.

A solution of the relation for $\hat{\gamma}=90^{\circ}$ and $\mathrm{Zr}=0$ is 10.28 atom percent niobium. As indicated, this solution ought to be an extrapolation of the location of the $\alpha^{\prime} / \alpha^{\prime \prime}$ boundary in the binary uranium-niobium system, based on this observed mathematical relationship. 


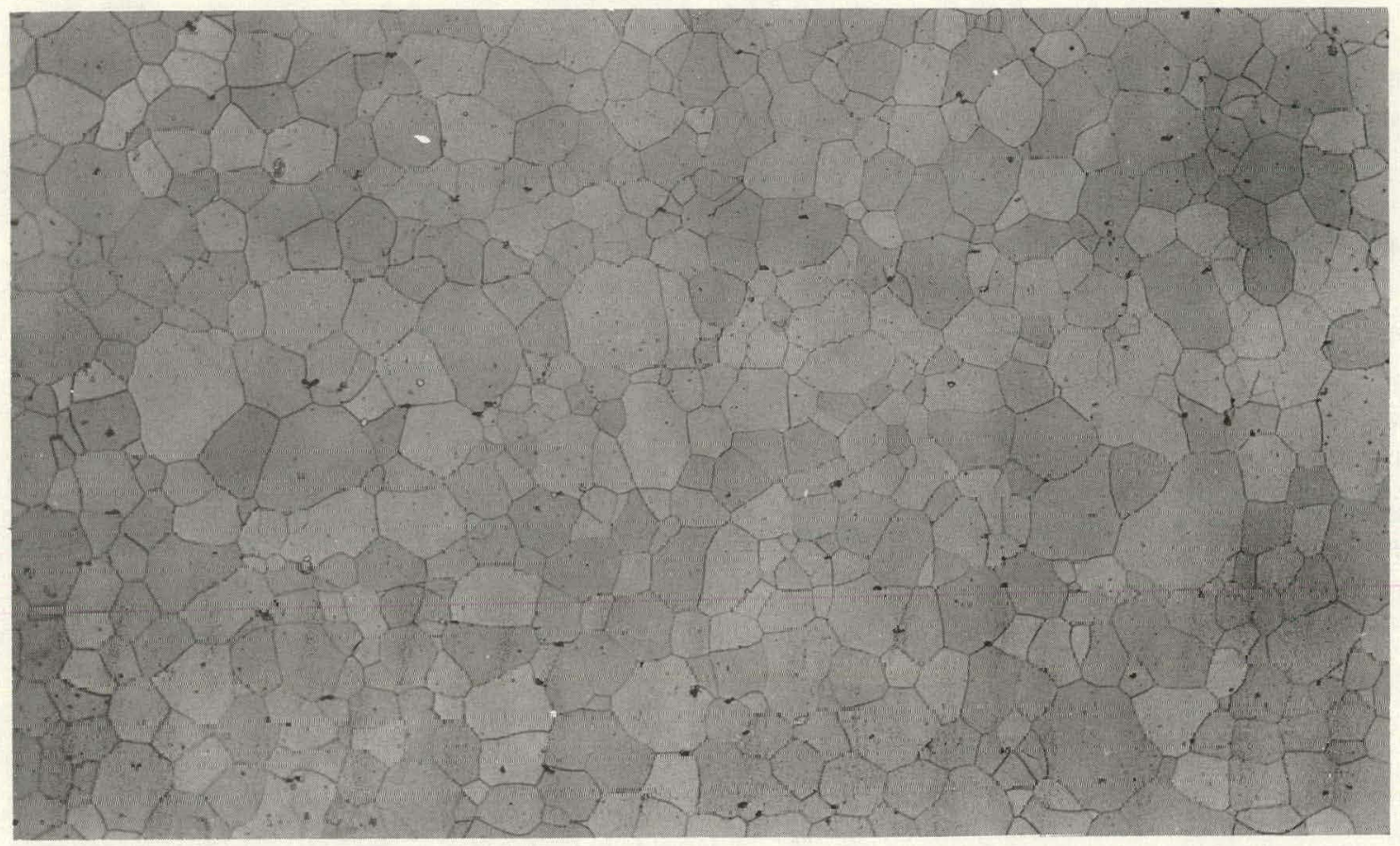

J326-2a

Figure 17. PHOTOMICROGRAPH OF A URANIUM-17.9 ATOM PERCENT NIOBIUM-2.3 ATOM PERCENT ZIRCONIUM ALLOY QUENCHED FROM $850^{\circ} \mathrm{C}$. (Oxalic Acid Etchant; 100X)

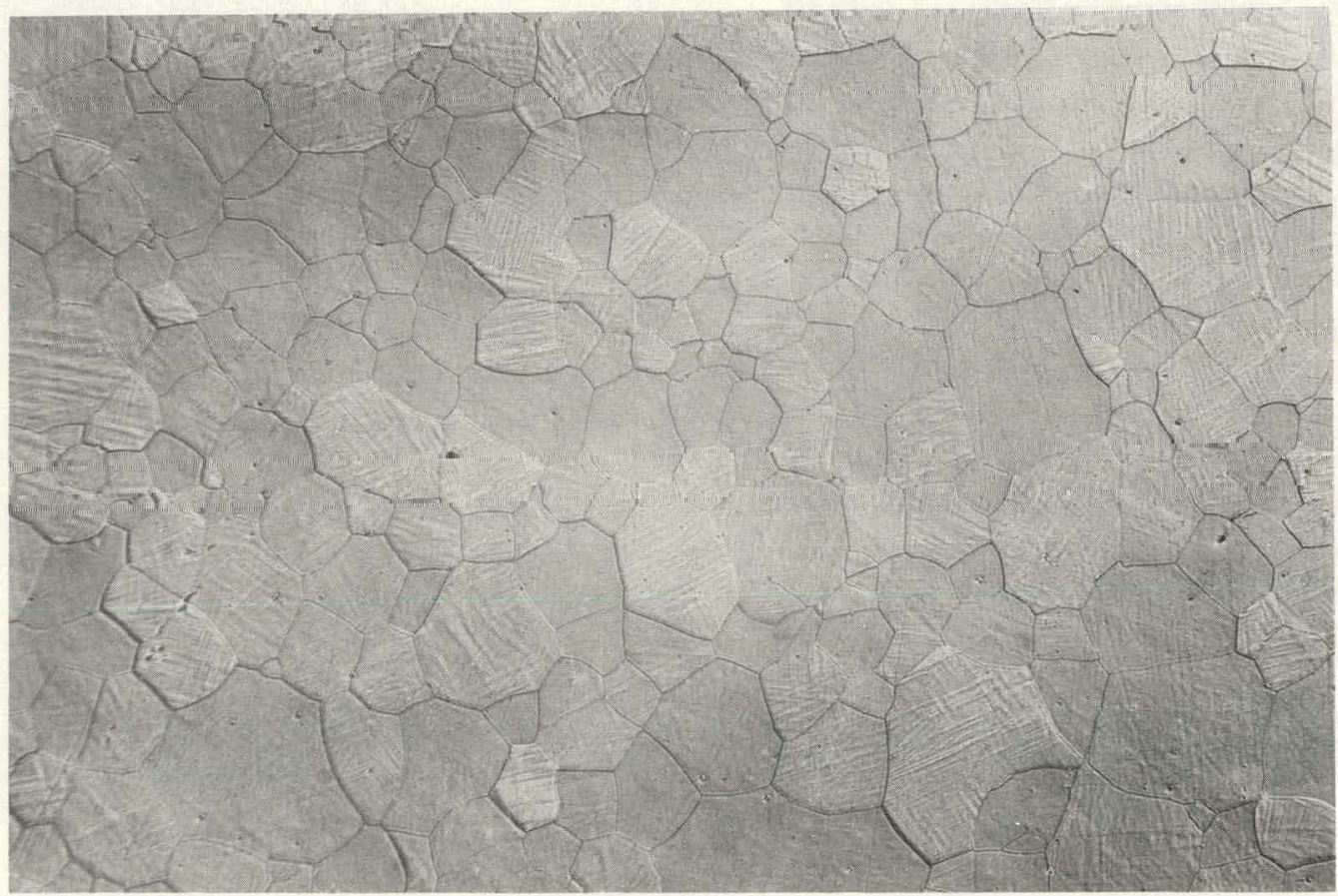

J326-8b

Figure 18. PHOTOMICROGRAPH OF A URANIUM-5.9 ATOM PERCENT NIOBIUM-13.3 ATOM PERCENT ZIRCONIUM ALLOY QUENCHED FROM $850^{\circ} \mathrm{C}$. (Oxalic Acid Etchant; 100X) 


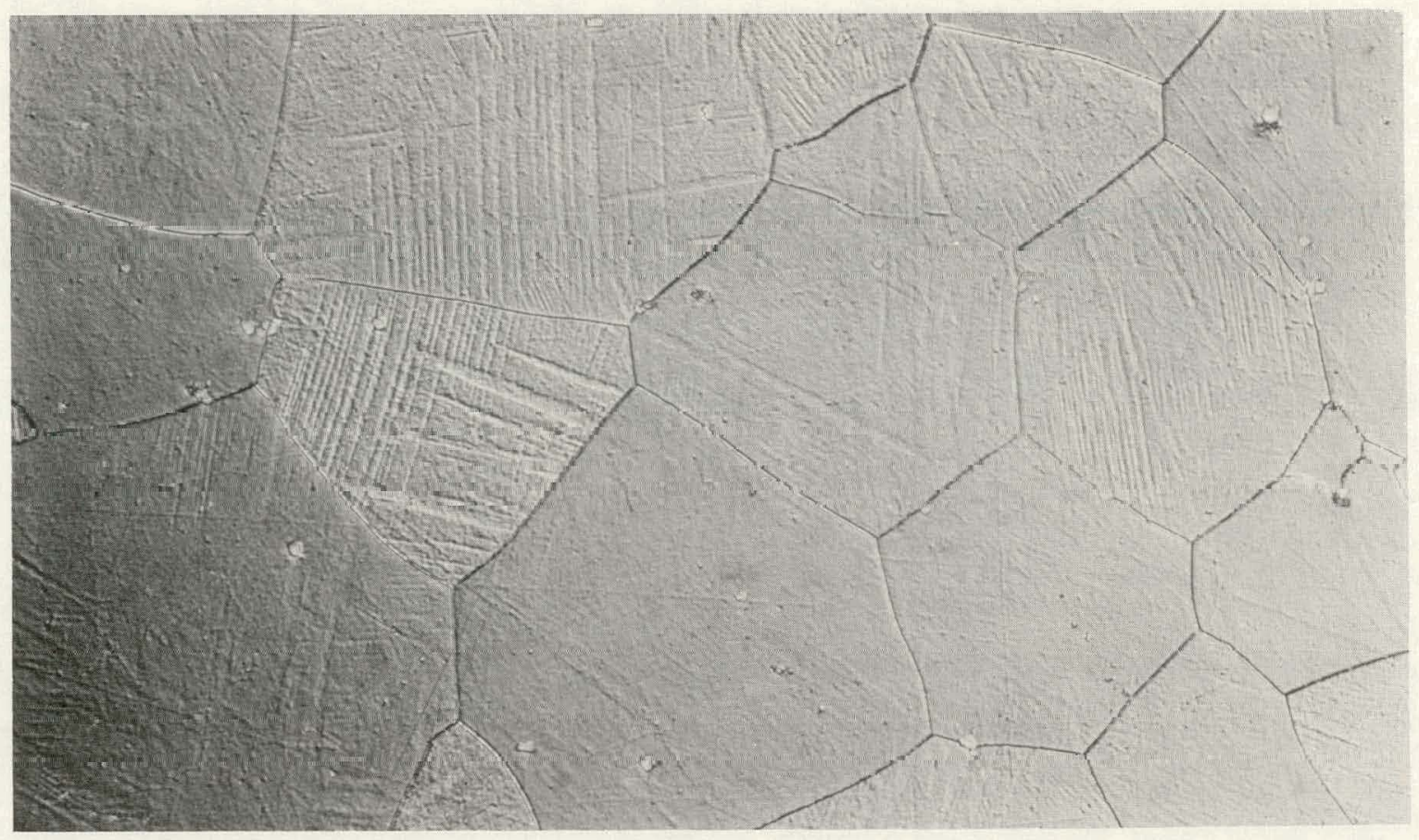

J326-8a

Figure 19. PHOTOMICROGRAPH OF A URANIUM-5.9 ATOM PERCENT NIOBIUM-13.3 ATOM PERCENT ZIRCONIUM ALLOY QUENCHED FROM $850^{\circ} \mathrm{C}$. (Note the Widmanstatten Structure; Oxalic Acid Etchant; 500X)

This value is encouraging since Tangri and Chaudhuri (13) have experimentally found the $\alpha^{\prime} / \alpha^{\prime \prime}$ boundary to lie between 10.0 and 11.2 atom percent niobium.

Furthermore, solving the monoclinic angle relation for $\hat{\gamma}=100^{\circ}$ and $\mathrm{Zr}=\mathrm{U}$, establishes a hypothetical $\alpha^{\prime \prime} / \gamma$ boundary at 22.8 atom percent niobium in the uranium-niobium system. Although this metastable phase boundary has not been observed in the uranium-niobium system, Jackson $(14)$ has recently reported the $\gamma^{n} / \gamma$ boundary to be at 21.0 atom percent niobium. The relatively close agreement between the extrapolation of Equation 2 for the alloy content needed to maintain the BCC phase at room temperature and the experimental determination of this value by Jackson $(14)$ is encouraging. Since the monoclinic angle has been shown to be influenced by the quenching rate and has also been observed to change reversibly with temperature cycling, $(30)$ the extrapolation of this 


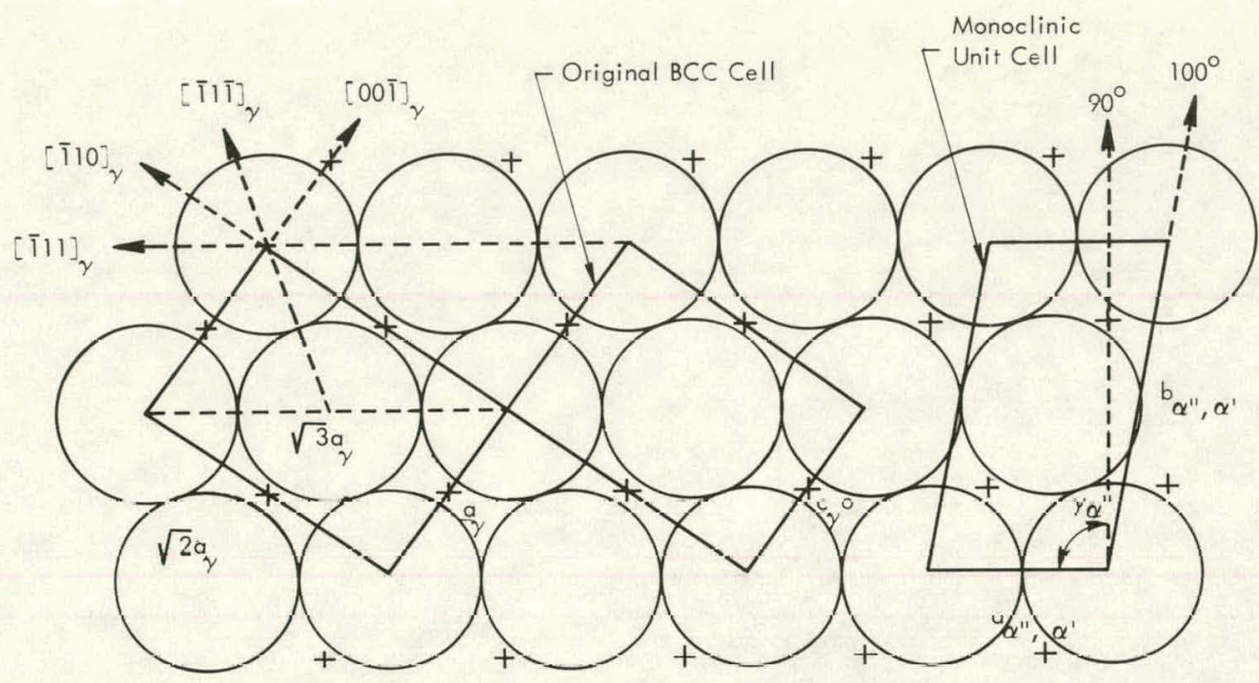

(a) Close-pack plane of the BCC structure.

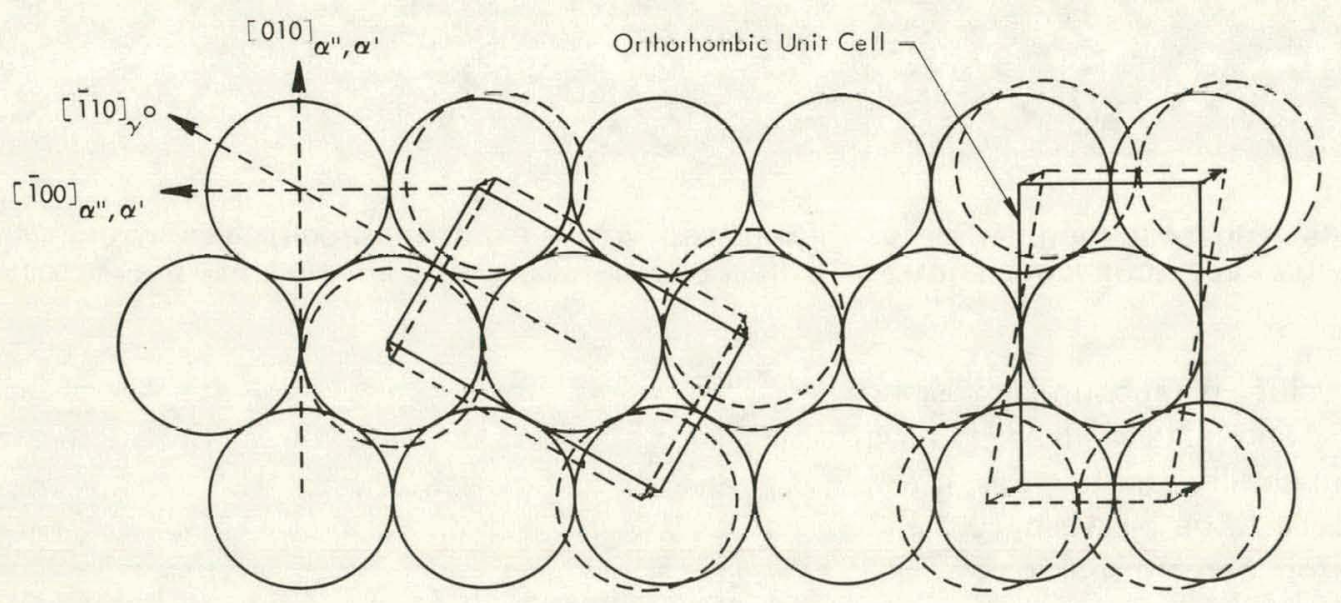

(b) Close-pack plane of a HCP structure.

Figure 21. MODELISTIC EXPLANATION FOR THE CONTINUITY OF THE $\gamma \rightarrow \alpha^{\prime \prime} \rightarrow \alpha^{\prime}$ TRANSFORMATIONS.

relationship ought not to be considered as a rigorous method for determining the critical composition for gamma stability and should only be applied to samples having similar annealing temperatures and quenching rates.

In the uranium-zirconium system, a hypothetical orthorhombic/monoclinic boundary can be predicted from Equation 2 at $\mathbf{2 2 . 8}$ atom percent zirconium. Since a monoclinic structure has not been observed in the uranium-zirconium system, the physical significance of this solution is not immediately apparent. However, it should be noted that the retention of gamma as a metastable room-temperature phase in the uranium-zirconium system has been observed in alloys containing between 24 and 25 atom percent zirconium. (18) 


\section{TWO-PHASE STRUCTURE}

The X-ray diffraction scan observed after quenching a U-8.0 Nb-17.4 $\mathrm{Zr}$ alloy from $850^{\circ} \mathrm{C}$ could not immediately be indexed on the basis of either a gamma-o or an alpha-double prime structure. However, these diffraction peaks could be indexed, assuming the presence of both a BCT and a monoclinic lattice. The lattice parameters calculated from the diffraction data for the apparent BCT and monoclinic lattices are: $a=4.95 \AA, c=3.49 \AA$, and $c / a=0.71 ;$ and $a=2.98 \AA, b=5.98 \AA, c=4.98 \AA$, and $\hat{\gamma}=95.2^{\circ}$, respectively. Quenching from a lower gamma-stabilizing temperature of $750^{\circ} \mathrm{C}$ did not clarify the situation.

The microstructure of the alloy after quenching from both 850 and $750^{\circ} \mathrm{C}$ is similar, and is illustrated in Figure 22. A review of this microstructure reveals some broadening of the grain boundaries and possibly a large number of inclusions. In view of the moderate levels of carbon and metallic impurities associated with this alloy (Table 1), it is unlikely that the apparent inclusions are the result of alloy contamination. Since the alloys were water quenched from high temperatures, it is unlikely that a second phase could have grown to the

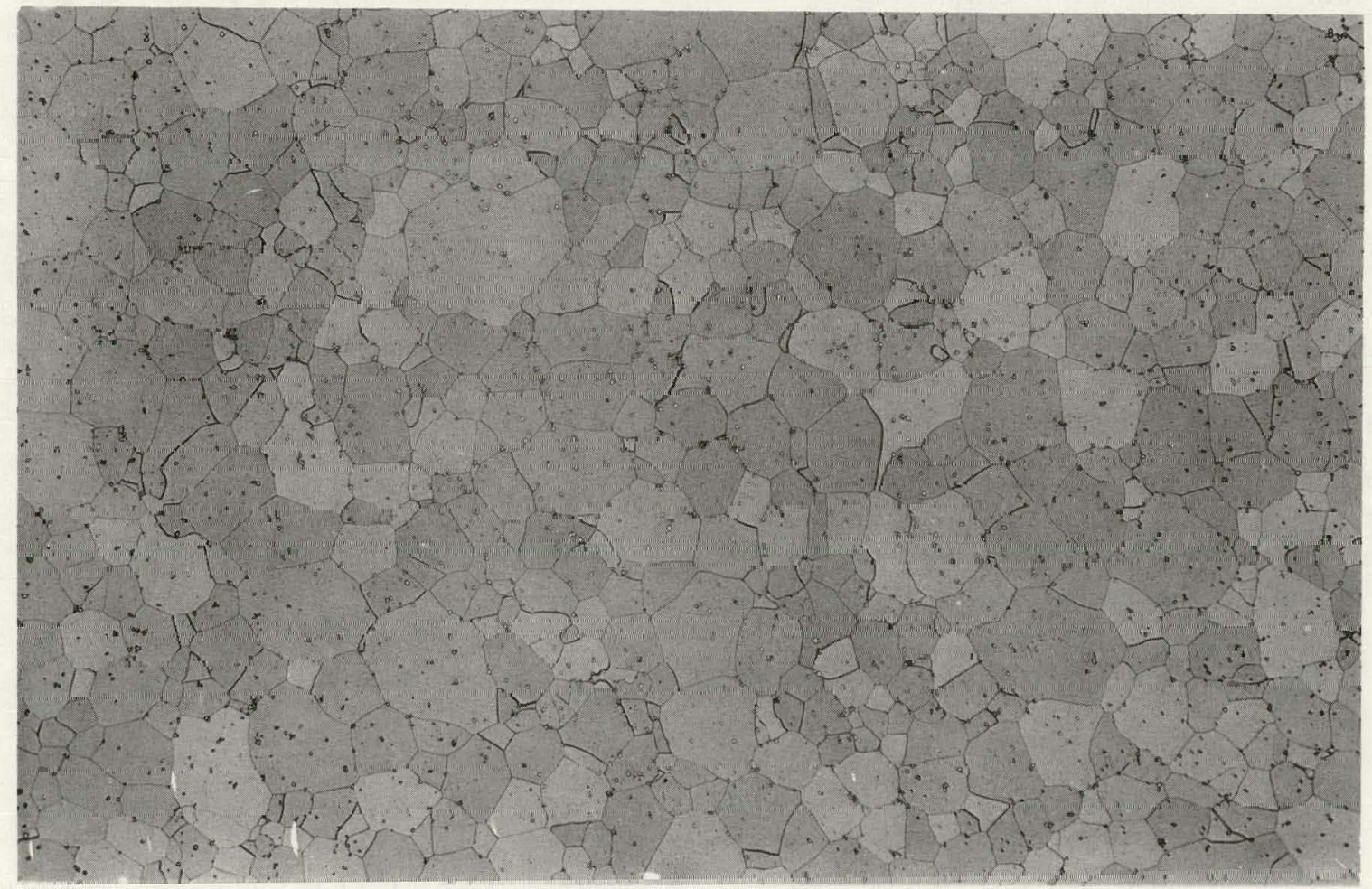

Figure 22. PHOTOMICROGRAPH OF A URANIUM-8.4 ATOM PERCENT NIOBIUM-17.4 ATOM PERCENT ZIRCONIUM ALLOY QUENCHED AT $850^{\circ} \mathrm{C}$ IN WHICH A TWO-PHASE STRUCTURE WAS OBSERVED IN THE X-RAY DIFFRACTION SCAN. (Oxalic Acid Etchant; 100X) 
size shown in Figure 22. In conclusion, no explanation of these observations can be given at this time.

\section{EFFECT OF QUENCHING FROM $750^{\circ} \mathrm{C}$}

As indicated previously, six alloys were water quenched from $750^{\circ} \mathrm{C}$ in an effort to determine the effect of the quenching temperature on the retention of the gamma-s, gamma-o, and alpha-double prime metastable phases. The six alloys are identified as 6, 8, 9, 10,11 , and 15 in Table 2, and were originally found to have the following metastable phases present as a result of the $850^{\circ} \mathrm{C}$ anneal: $\alpha^{\prime \prime}, \gamma^{\mathrm{O}}, \gamma^{\mathrm{S}}, \gamma^{\mathrm{s}}, \gamma^{\mathrm{s}}$, and $\gamma$.

The U-17.0 Nb-2.3 $\mathrm{Zr}$ alloy (Sample 8) was the only one found to have a BCT structure following the original $850^{\circ} \mathrm{C}$ anneal. A review of the diftraction intensity scan following the $750^{\circ} \mathrm{C}$ anneal indicated that this crystal symmetry was maintained; however, a reduction in the c/a ratio was noted as a result of quenching from the lower annealing temperature. This apparent reduction in the c/a ratio with a decreasing annealing temperature has also been observed by Vandermeer. (31) In his experiment, quenching of specimens of a U-16.6 Nb-5.64 $\mathrm{Zr}$ alloy was interrupted by quenchıng the specimen into an intermediate salt bath held at varying temperatures for 30 minutes before a final ice-water quench. The resulting relation between the $c / a$ ratio and the salt-bath temperature is illustrated in Figure 23.

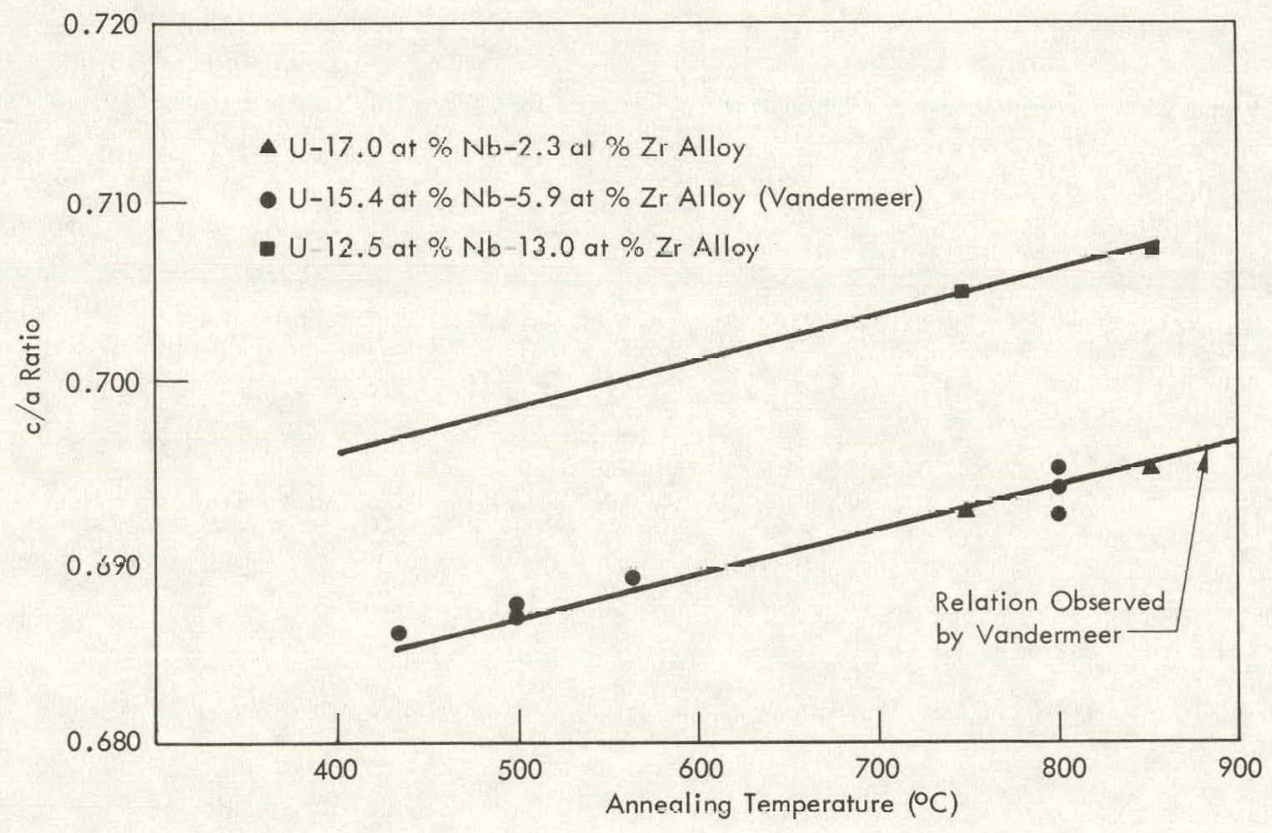

Figure 23. VARIATION OF THE c/a RATIO WITH THE ANNEALING TEMPERATURE FOR THREE URANIUM-NIOBIUM-ZIRCONIUM TERNARY ALLOYS.

The triangular datums in this figure are the results from quenching the U-17.0 Nb-2.3 $\mathrm{Zr}$ alloy (an alloy approaching the composition of Vandermeer's alloy) from this study from both 850 and $750^{\circ} \mathrm{C}$. These datums appear to agree closely with Vandermeer's observations. A subsequent review of the results of quenching a U-12.5 Nb-13.0 Zr alloy 
from both 850 and $750^{\circ} \mathrm{C}$ revealed a significant deviation from this c/a ratio to the annealing-temperature relation. On quenching this alloy from $850^{\circ} \mathrm{C}$, a BCC lattice was observed which can be expressed as a BCT lattice with a c/a ratio of 0.707 . Subsequent annealing and quenching from $750^{\circ} \mathrm{C}$ resulted in a BCT lattice with a c/a ratio of 0.705 . An evaluation of the location of these points in Figure 23 strongly indicates that these points do fit the same relation observed by Vandermeer, but are displaced from it by a constant amount. Therefore, a line having the same slope as that suggested by Vandermeer does fit through these datums. This hypothetical curve fit suggests that a family of curves probably exists which relate the c/a ratio of gamma-o structures to the annealing temperature. The specific curve followed is probably a function of the alloy content.

Subsequent evaluation of a U-17.4 Nb-5.4 $\mathrm{Zr}$ alloy and a U-14.5 Nb-8.7 $\mathrm{Zr}$ alloy (Samples 9 and 10 , respectively) both revealed no apparent change in the lattice structure or lattice parameter as a result of quenching from 850 to $750^{\circ} \mathrm{C}$. A review of the total alloy content and the niobium-to-zirconium ratio for these two alloys indicate that they both are approaching the range of these variables for the alloy used by Vandermeer and the two previously discussed alloys. In view of this relative similarity in alloy content and ratio, an agreement with the c/a ratio-versus-annealing temperature relation observed previously was anticipated but was not observed.

In addition to these alloys, the structure of a U-13.4 Nb-4.6 $\mathrm{Zr}$ alloy (Sample 6) was evaluated for change as a result of annealing at 850 and $750^{\circ} \mathrm{C}$. After the original quench from $850^{\circ} \mathrm{C}$, this alloy was found to have monoclinic symmetry. Quenching from $750^{\circ} \mathrm{C}$ also produced a monoclinic lattice; however, a comparison of the monoclinic lattice parameter revealed a decrease in the $a, b, c$, and $\hat{\gamma}$ dimensions. This general contraction resulted in a $1.06 \%$ decrease in the unit cell volume per atom. The significance of this decrease is nnt known at this time.

\section{RELATIONSHIP BETWEEN ALLOY CONTENT AND MICROHARDNESS}

As indicated earlier, microhardness values were obtained from all samples. Subsequent evaluation of these data, using the stepwise multilinear regression described previously, revealed a strong relationship between microhardness and $\mathrm{Nb}^{2}$ and $\mathrm{Zr}$ (atom percent). The mathematical form of this relation is:

$$
\begin{aligned}
& D P H=K_{1}+K_{2} N^{2}+K_{3} Z r \\
& K_{1}=44.9 \pm 44.0 \\
& K_{2}=0.45 \pm 0.10 \\
& K_{3}=8.8 \pm 1.7,
\end{aligned}
$$

while Figure 24 illustrates this observation graphically.

A review of Figure 24 reveals several important points. First, no detectable discontinuities in this relation were observed at any of the phase-transformation boundaries, which tends to reemphasize the progressive nature of the atom displacements associated with the 
$\gamma \rightarrow \gamma^{S} \rightarrow \gamma^{0} \rightarrow \alpha^{\prime \prime}$ transformations. Secondly, this relation suggests that niobium is more potent in stiffening the lattice than zirconium.

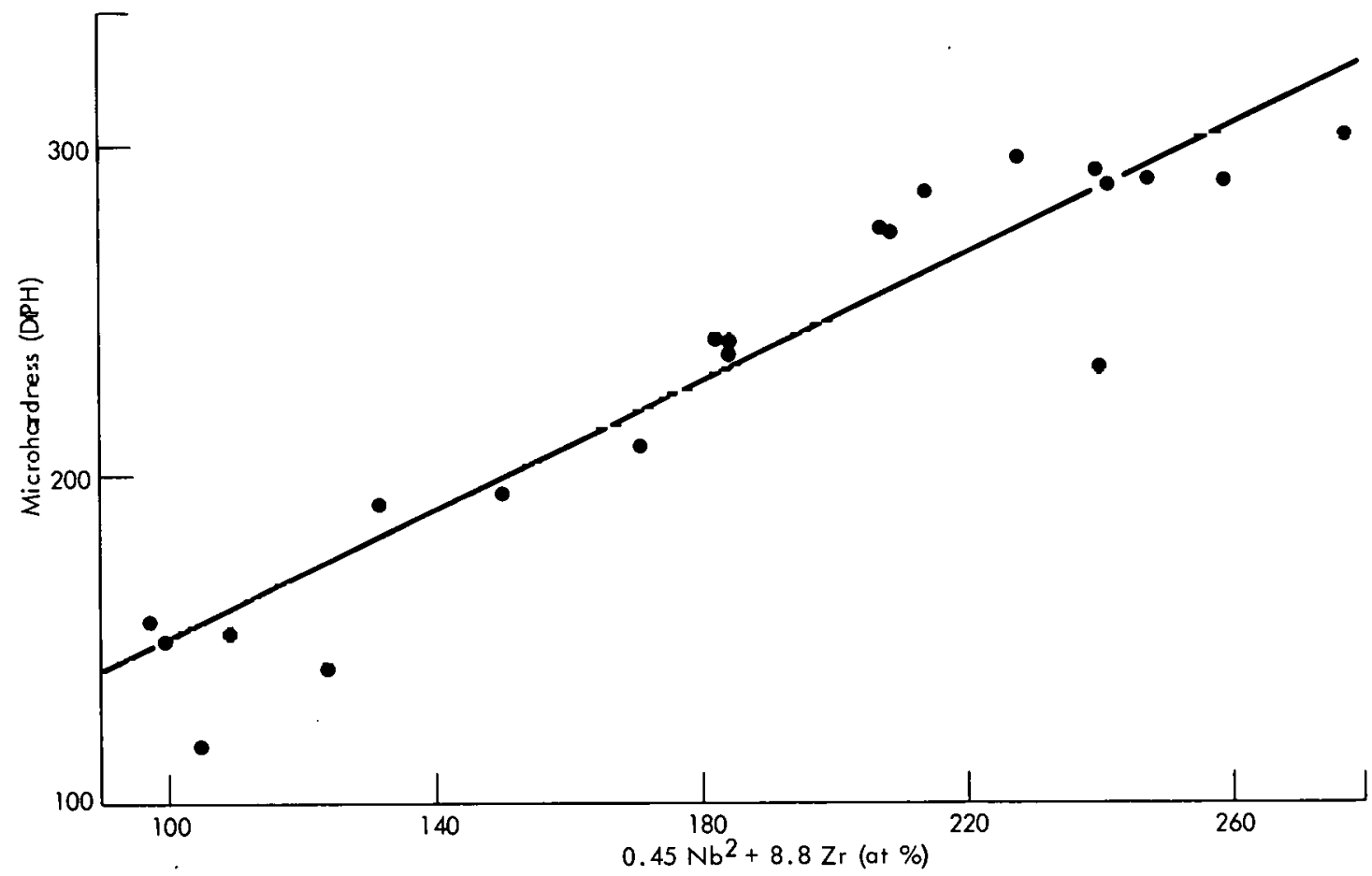

Figure 24. A COMPARISON OF THE VARIATION IN THE OBSERVED DPH HARDNESS WITH THE NIOBIUM AND ZIRCONIUM CONTENT AS A FUNCTION OF DPH $=44.9+0.45 \mathrm{Nb}^{2}+8.8 \mathrm{Zr}$.

In an effort to confirm the validity of this relation, a review of the literature was initiated to determine if a similar correlation between miçöharaness and alloy content had beelı observed in the uranium-niobium, uranium-zirconium, or uranium-molybdenum systems. These efforts indicated that no sufficiently comprehensive study of microhardness versus alloy content has been carried out on any of these alloy systems.

\section{TRANSITIONAL PHASE DIAGRAM}

By plotting the approximate position of the 20 alloys produced in this experiment, plus the two alloys studied by Vandermeer, (31) a possible extension of Jackson's(14) "transitional phases diagram" for the uranium-niobium binary system into the uranium-rich portion of the uranium-niobium-zirconium ternary system could be proposed. In constructing this ternary transitional phase diagram, the phase boundaries were located empirically with regard to the experimental results cited in Vandermeer's paper and the transitional boundaries previously reported for the uranium-niobium and uranium-zirconium systems. In each case, these boundaries have been drawn as straight lines since this is both compatible with the experimental data and is suggested by the models of $A_{0}$ and $\hat{\gamma}$ versus the niobium and zirconium contents (Equations 1 and 2). A detailed discussion of the placement of each boundary follows. 
As indicated earlier, a review of the atom placement in a monoclinic lattice indicates that at $\hat{\gamma}=90^{\circ}$, the monoclinic and orthorhombic lattices are similar. Therefore, a portion of the $\alpha^{\prime} / \alpha^{\prime \prime}$ boundary, shown in Figure 25, was obtained by plotting the locus of solutions of the monoclinic angle versus atom percent niobium and zirconium relation (Equation 2) for $\hat{\gamma}=90^{\circ}$. Since the existence of a monoclinic phase in the uranium-zirconium system has not been reported, the validity of this boundary at low niobium concentration is not certain. Therefore, as this boundary approaches the uranium-zirconium binary portion of the ternary system, some curvature was added to this boundary such that the boundary intersects the critical composition for gamma-phase retention in the uranium-zirconium binary. ${ }^{(18)}$ In this manner, the shape of the $\alpha^{\prime} / \alpha^{\prime \prime}$ boundary more closely agrees with that proposed by Dwight and Mueller(21) and also does not suggest the existence of alpha-double prime in the uranium-zirconium binary system.

Subsequent comparison of the placement of the $\alpha^{\prime} / \alpha^{\prime \prime}$ boundary in this study to that proposed by Dwight and Mueller(21) (Figure 7) indicates that the Dwight and Mueller(21) boundary is shifted toward alloys of higher niobium and zirconium contents. A review of

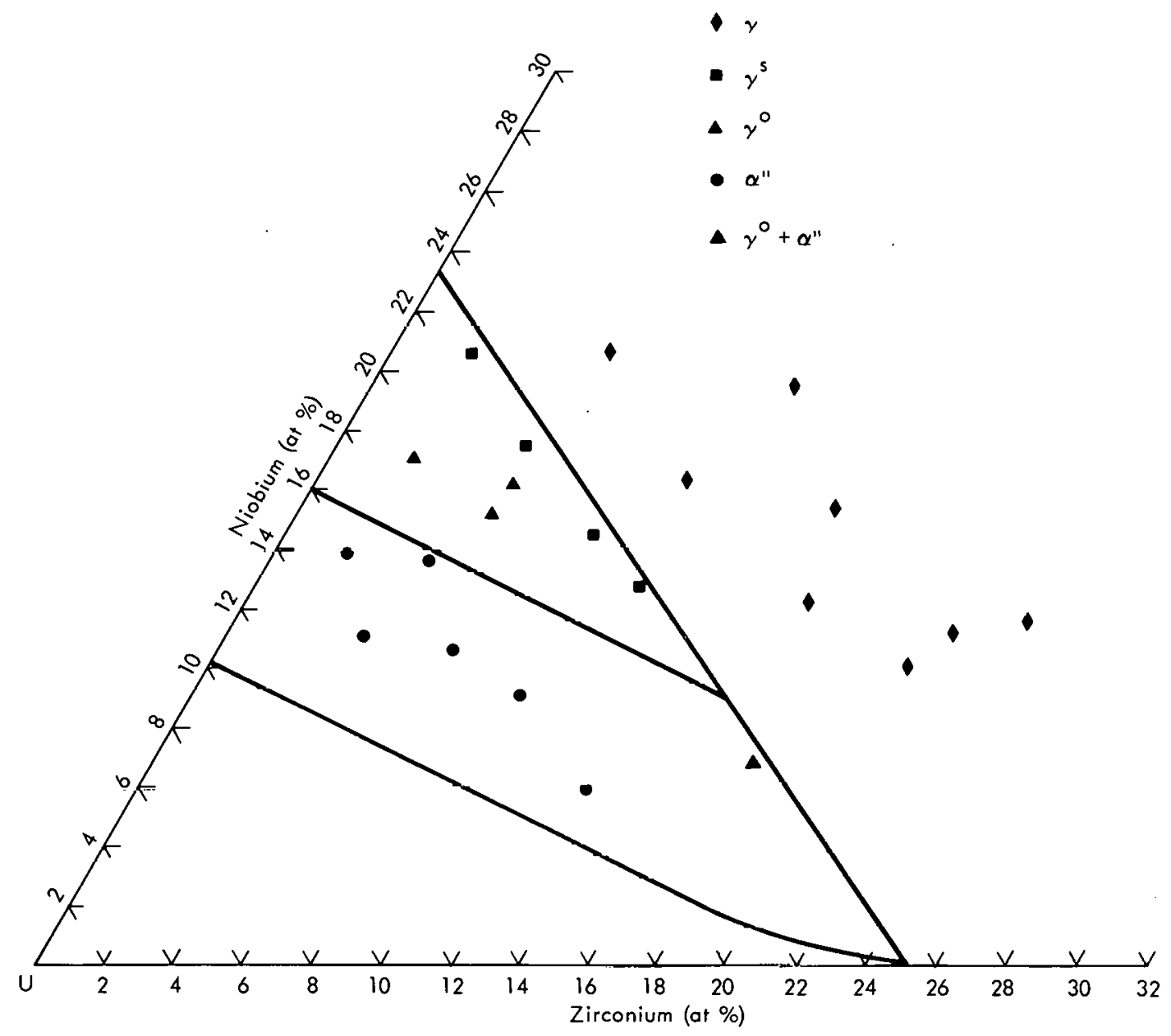

Figuro 25. PROPOSED TRANEITIONAL PHASE3 DIAGRAM FOR THE URANIUM-NIUBIUM-ZIRCONIUM TERNARY ALLOY SYSTEM. 
the Dwight and Mueller $(21)$ report suggests that a possible explanation for this discrepancy is that their positioning of the $\alpha^{\prime} / \alpha^{\prime \prime}$ transitional phase boundary was based on a limited number of samples.

Placement of the $\alpha^{\prime \prime} / \gamma^{0}$ boundary was also determined by solving the monoclinic angle versus niobium and zirconium relation for a locus of solutions. Efforts leading to this solution were initiated by first noting that Tangri $(13)$ had observed the $\alpha^{\prime \prime} / \gamma^{\circ}$ boundary in the uranium-niobium binary alloy at 16 atom percent niobium. Using Equation 2, this alloy concentration would be anticipated to yield an alpha-double prime phase with a monoclinic angle parameter of 94.4 degrees. In accordance with the transformation model illustrated in Figu ure 21 (a), the $\gamma \rightarrow \alpha^{\prime \prime}$ transformation of this 16 atom percent niobium alloy would have resulted in a shear in the (111) direction that would change the monoclinic angle by 5.6 degrees. This observation suggests that in an alloy where a shear distortion $(100-\hat{\gamma})$ of less than 5.6 degrees is predicted, the $\gamma \rightarrow \gamma^{\circ}$ reaction is favored. Conversely, if in an alloy where the resulting shear displacement is greater than 5.6 degrees on quenching, the $\gamma \rightarrow \alpha^{\prime \prime}$ reaction is energetically more favored than the competing $\gamma \rightarrow \gamma^{0}$ reaction. Applying this rationale to the ternary uranium-niobium-zirconium system, the $\alpha^{\prime \prime} / \gamma^{0}$ boundary was assumed to be the locus of solutions of Equation 2 for 94.4 degrees.

Figure 25 suggests that a hypothetical $\gamma^{0} / \gamma^{S}$ boundary could be drawn between 21 atom percent niobium and 27.2 atom percent zirconium binary alloys and would be in agreement with the experimental observations. However, this $\gamma^{0} / \gamma^{s}$ boundary was not included since it can be argued that gamma-o and gamma-s are not uniquely different phases. As indicated earlier, Yakel(24) has suggested that the mechanism for both the $\gamma \rightarrow \gamma^{\mathrm{S}}$ and $\gamma \rightarrow \gamma^{0}$ transformations is the coordinated shift of body-centered atoms along $\langle 100\rangle_{\gamma}$ directions. In the gamma-s phase, $\langle 100\rangle_{\gamma}$ shifts are realized throughout the material; however, a correlated shift in specific $\langle 100\rangle_{\gamma}$ directions occur only over a small number of unit cells, and the average structure remains cubic. In the gamma-o structure, the common shift direction extends over a significantly longer distance in one $[100] \gamma$ direction, resulting in a tetragonal structure vielding a detectable c/a ratio. (32) Vandermeer (31) suggests that the volume of material where atoms are shifted in common directions is a domain. Assuming that domain size could be influenced by alloy content suggests that the apparent $\gamma^{0} / \gamma^{s}$ boundary observed in these data merely reflects the critical domain size at which the resulting c/a can be resolved.

A review of the results of samples of higher alloy content suggests that a boundary should exist between alloys which demonstrate no distortion of their BCC lattice on quenching and those that develop atomic displacements on quenching characterized by superlattice peaks. Such a boundary is shown in Figure 25. The location of this boundary was derived arbitrarily by connecting the limiting alloy levels required to maintain metastable gamma at room temperature for both the uranium-niobium and the uranium-zirconium binary systems and appears to agree with the results of this experiment. 


\section{CONCLUSIONS AND RECOMMENDATIONS}

This investigation was concerned with determining the metastable phases produced as a result of quenching various alloys from the uranium-rich corner of the uraniumniobium-zirconium ternary system from $850^{\circ} \mathrm{C}$. A summation of the more important conclusions and recommendations related to this investigation follows.

Evaluation of the $\mathbf{2 0}$ alloys used in this experiment revealed the following four transitional phases: $\alpha^{\prime \prime}$ (monoclinic), $\gamma^{\mathrm{O}}$ (body-centered tetragonal), $\gamma^{\mathrm{s}}$ (displaced BCC), and retained $\gamma$ $(B C C)$. By noting the grouping of alloys of similar transitional phases plus utilization of other experimental observations, a hypothetical room-temperature transitional phase diagram for the uranium-rich section of the ternary system was proposed. Although the general shape of this transitional phase diagram is similar to that proposed by Dwight and Mueller, (21) several significant differences were observed. For example, the $\alpha^{\prime} / \alpha^{\prime \prime}$ boundary in this diagram was found to be displaced from the Dwight and Mueller (21) boundary in the direction of lower alloy content by 2 to 3 atom percent. In addition, an area of gamma-o stability was also observed; however, this area was found to be compressed significantly from that proposed by Dwight and Mueller. (21) In view of the results of previous experimenters, it should be noted that this proposed transitional phase diagram could be significantly influenced by impurity levels, quench rates, and annealing temperatures; therefore, this apparent phase relation should be considered accurate only for material of equal purity and similar heat treatment.

An in-depth evaluation of the alloys demonstrating monoclinic crystal symmetry revealed no statistically significant relation between the $a, b$, and $c$ lattice parameters and alloy content. However, the monoclinic angle was found to be related to the niobium and zirconium content by the following relation: $\hat{\gamma}=82.0+0.774 \mathrm{Nb}+0.349 \mathrm{Zr}$. The validity of this expression was demonstrated by extrapolating the location of both the $\alpha^{\prime} / \alpha^{\prime \prime}$ and $\gamma^{0} / \gamma$ boundaries in the uranium-niobium system and comparing the location of these boundaries to those observed by Tangri(13) and Jackson. (14) In addition, a review of the microstructure of these samples revealed a faint acicular or Widmanstatten structure. Similar microstructures have been reported in quenched samples of dilute uranium-niobium alloys and isothermally transformed uranium-niobium-zirconium ternary alloys.

Pooling the lattice-parameters data obtained from the gamma and gamma-s material revealed a linear relation between the BCC lattice parameters and alloy content. The equation for this relation is $A_{o}=3.479-0.0013 \mathrm{Nb}+0.00129 \mathrm{Zr}$. This apparent linear dependence of lattice parameter with alloy content follows Vegard's Law. In addition, extrapolation of this relation to zero niobium and zirconium contents yielded an apparent room-temperature BCC lattice parameter for gamma uranium of $3.479 \AA$, which agrees closely with a similar extrapolation made by an investigator in the uranium-molybdenum binary system.

The relative location and intensity of the superlattice peaks associated with gamma-s and gamma-o were compared with Yakel's $(24)$ calculated location and relative intensity of the superlattice peaks based on his displacement model and Tangri's ${ }^{(25)}$ chemically ordered lattice. Yakel's displacement model was found to more accurately describe the locations and intensities of the superlattice peaks in both the gamma-s and gamma-o materials. 
The results of quenching selected samples from both 850 and $750^{\circ} \mathrm{C}$ revealed a compliance with the relationship between the $\mathrm{c} / \mathrm{a}$ ratio in gamma-o material to the annealing temperature previously observed by Vandermeer.(31) Evaluation of an additional alloy quenched from varying annealing temperatures suggested the possibility that a family of c/a versus annealing temperature curves may exist and that the specific curve followed could be a function of the alloy content. In this vein, additional investigations of materials of varying alloy content, annealing temperature, and quenching rate are needed in an effort to more accurately characterize this apparent variation in the c/a ratio.

As indicated earlier, the transitional phase diagram for the uranium-niobium-zirconium ternary developed in this study is applicable only to alloys of equal purity and materials quenched at comparable cooling rates and annealed from equal temperatures. In actual practice, control of these additional factors is not always practical; therefore, an analogous investigation should be made at varying annealing temperatures, quench rates, and interstitial impurity levels in an effort to determine the impact of these variables on the transitional phase diagram. In addition, numerous alloys from the gamma-o region should be fabricated and evaluated to more accurately define the boundaries of this area. Furthermore, additional alloys from near the uranium-zirconium binary should be investigated to more accurately identify the apparent two-phase structure observed in this experiment and also to determine the range of compositions within which this possible two-phase structure exists. 


\section{REFERENCES}

(1) McLennan, J. C. and McKay, R. W.; "Crystal Structure of Uranium", Trans Roy Soc, 24, p $1(1930)$.

(2) Wilson, T. A.; "Crystal Structures of Uranium", Physic, 4, p 148 (1933).

(3) Struchen, E. F.; "The Atomic Position Parameter in Alpha Uranium", Acta Cryst, 13, p 852 (1960).

(4) Gittus, J. H.; Uranium, p 256; Butterworth, Washington (1963).

(5) Holden, A. N.; Physicak Met of Uran, Addison-Wesley Publishing Company, Reading, Massachusetts (1958).

(6) Chiotti, P.; "Magnesium-Uranium System", Tran Amer Inst Min Eng, 206, p 562 (1958).

(7) Sawyer, B.; The Uranium-Columbium Alloy System, Argonne Report ANL 4027 (1947).

(8) Pfeil, P. C. L., Brown, J. D., and Williamson, G. K.; "The Uranium-Niobium Alloy System in the Solid State", J Inst Meta/s, 87, pp 204 - 208 (1958 - 1959).

(9) Rogers, B. A., Atkins, D. F., Mantos, E. J., and Kirkpatrick, M. E.; "UraniumColumbium Alloy Diagram", Trans AIME, 212, pp 387 - 393 (1958).

(10) Hatt, B. A.; "The Orientation Relationship Between the Gamma and Alpha Structure in Uranium-Zirconium Alloys", .I Nucl Mater, 19, (2), pp 133 - 141 (1966).

(11) Anagnostides, M., Columbie, M., and Monto, H.; "Metastable Phases in UraniumNiobium Alloys", J Nuc/ Mater, 11, (1), pp 67 - 76 (1964).

(12) Tangri, K. and Williams, G. I.; "Metastable Phases in the Uranium-Molybdenum System and Their Origin", J Nucl Mater, 4, (2), pp $226-233$ (1961).

(13) Tangri, K. and Chaudhuri, D. K.; "Metastable Phases in Uranium Alloys with High Solute Solubility in the BCC Gamma Phase. Part I - The System U-Nb", J Nucl Mater, 15, (4), pp $278-287$ (1965).

(14) Jackson, R. J.; Reversible Martensitic Transformations between Transitional Phases of Uranium Based Niobium Alloys, REP-1535; Dow Chemical Comnany - Rocky Flats Division, Golden, Colorado; December 23, 1970.

(15) Summer-Smith, J.; "The Constitution of Uranium-Zirconium Alloys", J Inst Metals, 83, pp 277 - 282 (1954 - 1955).

(16) Duffey, J. F. and Bruch, C. A.; "Della Phase Fleld in the U-Zrr Equilibrium Diagram", Trans AIME, 212, pp $17-19$ (1958). 
(17) Elliott, R. P.; Constitution of Binary Alloys, First Supplement; McGraw-Hill, New York (1965).

(18) Virot, A.; "Characteristics of a 6 wt \% Zirconium-Uranium Alloy", J Nucl Mater, 5, (1), pp 190 - 219 (1962).

(19) Hills, R. F., Butcher, B. R., Howlett, B. W., and Stewart, D.; "The Effect of Cooling Rate on the Decomposition of the $\gamma$-Phase in Uranium-Zirconium Alloys", $J$ NuCl Mater, 16, (1), pp 25 - 38 (1965).

(20) Storhok, V. W., Bauer, A. A., and Dickerson, R. F.; Survey of Ternary and Quaternary Metastable Gamma-Phase Uranium Alloys, BMI-1278; Battelle Memorial Institute, Columbus, Ohio, July 15, 1958.

(21) Dwight, A. E. and Mueller, M.H.; Constitution of the Uranium-Rich U-Nb and U-Nb-Zr Systems, ANL-5581; Argonne National Laboratory, Lemont, Illinois; October 1957.

(22) Dean, C. W.; A Study of the Time-Temperature Transformation Behavior of a Uranium-7.5 Weight Percent Niobium-2.5 Weight Percent Zirconium Alloy, Y-1694; Union Carbide Corporation-Nuclear Division, Oak Ridge Y-12 Plant, Oak Ridge, Tennessee; October 24, 1969.

(23) Giraud-Heraud, F. et Guillaumin, J.; "Formation de Phased de Transition dans I'alliage U-7.5\% Nb-2.5\% Zr", Acta Met, 21, (9), pp 1243 - 1252 (1973).

(24) Yakel, H. L.; "Crystal Structures of Transition Phases Formed in. U/16.60 at \% $\mathrm{Nb} / 5.64$ at \% Zr Alloys", J Nucl Mater, 33, pp 286 - 295 (1969).

(25) Tangri, K.; "Les Phases Gamma Metastable dans les Alliages d'Uranium Contenant du Molybdene", Met Sci Rev Met, 58, (6), pp 469 - 478 (1969).

(26) Baucum, W. E., Carpenter, D. A., Bearden, L. E., and Sells, K. A.; Determination of a Search-Scan Computer-Assisted Data Analysis Method, Y-1946; Union Carbide Corporation-Nuclear DIvlsion, Oak Ridye Y-12 f'lant, Ulak Fidge, Tennessce; July 1974.

(27) Wilson, A. S. and Rundle, R. E.; "The Structure of Uranium Metal", Acta Cryst, 2, (2), pp $126-127$ (1949).

(28) Vegard, L. Z.; “Die Konstitution der Mischkristalle und die Ramfullung der Atome", Physic, 15, p 17 (1921).

(29) Lehmann, J. and Hills, H. F.; "Proposed Nomenclature for Phises iri Uranium Alloys", J Nucl Mater, 2, (3), pp 261 - 268 (1960).

(30) Stewart, D. and Williams, G. I.; "The Structure and Occurrence of the Metastable Monoclinic Phase, $a^{\prime \prime}$, in Uranium-Molybdenum Alloys", J Nucl Mater, 20, pp 262 - 268 (1966). 
(31) Vandermeer, R. A.; Recent Observation of Phase Transformations in a U-Nb-Zr Alloy, Paper Presented at the Physical Metallurgy of Uranium Alloys Conference, Jointly Sponsored by the USAEC and Army Material and Mechanics Research Center; Vail, Colorado; February 12 - 14, 1974.

(32) Yakel, H. L.; A Review of X-Ray Diffraction Studies in Uranium Alloys, Paper Presented at the Physical Metallurgy of Uranium Alloys Conference, Jointly Sponsored by the USAEC and Army Material and Mechanics Research Center; Vail, Colorado; February 12 - 14, 1974. 


\section{ACKNOWLEDGEMENTS}

The author is particularly grateful to his advisor, R. A. Vandermeer, for his patience throughout the course of this investigation and for his invaluable assistance in preparing the final manuscript.

Thanks are extended to the following employees of the Oak Ridge Y-12 Plant who contributed to this research: W.J. Hulsey, for his suggestion of this research topic; P. G. Petretzky and staff, for the metallography and microhardness work; W. A. Agee and C. C.arson for their assistance in melting and fabricating the alloys; and B. N. Price and P. C. Weaver for initial typing of this manuscript. 
Distribution

Energy Research and Development

Administration - Oak Ridge

Hickman, H. D.

Leed, R. E.

Zachry, D. S., Jr

Holifield National Laboratory

Vandermeer, R. A.

Oak Ridge Gaseous Diffusion Plant

Stief, S. S.

Wilcox, W. J., Jr

\section{Oak Ridge Y-12 Plant}

Alvey, H. E.

Bernander, N. K.

Burditt, R. B.

Burkhart, L. E.

Cadden, J. L.

Cooper, R. H. (6)

Ebert, T. H.

Ellingson, R. D.

Fraser, R. J.

Gritzner, V. B.

Jackson, V. C.

Jones, F. W.

Kahl, K. G.

Keith, A.

Kite, H. T.

Koger, J. W.

Lundin, M. I.

McElroy, B. D.

Mills, J. M., Jr

Phillips, L. R.

Schreyer, J. M.

Smith, H. F., Jr

Smith, R. D.

Stoner, H. H.

Tewes, W. E.
Tilson, F. V.

Yaggi, W. J./Googin, J. M.

$Y-12$ Central Files (5)

$Y-12$ Central Files (master copy)

$Y-12$ Central Files (route copy)

$Y-12$ Central Files ( $Y-12 R C)$

Zava, A. K.

Zerby, C. D.

Paducah Gaseous Diffusion Plant Levin, R. W.

In addition, this report is distributed in accordance with the category UC-25, Materials, as given in the USERDA Standard Distribution Lists for Unclassified Scientific and Technical Reports, TID-4500. 